\title{
Thermodynamics and the Economic Process An application to World Energy Resources and Climate Change
}

\section{John Bryant}

VOCAT International Ltd, 10 Falconers Field, Harpenden, AL5 3ES, United Kingdom.

E-mail: john.bryant@vocat.co.uk

\begin{abstract}
This paper develops further a model of the economic process, first set out as part of a paper by the author published in 2007, concerning the application of thermodynamic laws to economics. The paper sets out relationships between economic output and capital, labour, resource and waste stocks, with specific reference to energy, and is backed up by analysis of data of world energy resources and climate change. The paper concludes that both energy resource availability and climate change will have significant, limiting effects on the forward path of economic development.
\end{abstract}

Keywords: Thermodynamics, economics, entropy, energy, exergy, peak oil, gas, coal, climate change

JEL Classification: A12, Q3, Q4, Q5

Biographical notes: John Bryant is director of VOCAT International Ltd, a company specialising in economic consultancy and research, and expert witness services. His prior career appointments have included group economist and manager corporate planning for multi-national corporations, and economist and investment analyst for a stock broking group. He first became interested in the relationship between economic theory and the laws of thermodynamics in 1974, and has published several papers on the subject since that time, culminating in a key paper published in 2007 [Bryant, J. (2007)].

1

Introduction

This paper develops a theory set out in a paper published by the author in 2007 [Bryant, J. (2007)], which described an analogy between economic and thermodynamic systems. The analogy is taken further, and particular aspects considered are the relationship of resources to production, and the impact of resource limitations on economic activity. The paper is illustrated empirically by reference to energy resources and climate change. The first part of this paper concerns economic stock definitions of capital, labour, resources and waste, the second part the connections between the stocks and the development of a production function, and the third part sets out analyses of world energy resources and climate change in relation to economic output to illustrate the principles.

To recapitulate from the original paper, for an ideal gas system made up of a number $\mathbf{N}$ of molecules, which are perfectly elastic and are busy moving about colliding with each other exchanging kinetic energy, the relationship of the system with the outside world is that it is contained in a volume $\mathbf{V}$ resulting in the gas exerting a pressure $\mathbf{P}$ on the boundaries of the system. If, through the application of heat, the gas molecules are made to vibrate and move about faster, they increase their rate of exchange of kinetic energy and the gas accumulates internal energy resulting in a temperature rise $\mathbf{T}$, with pressure and volume potentially increasing too. The relationship between the factors is given by the ideal gas equation:

$$
P V=N k T
$$

Where $\mathbf{k}$ is called the Boltzmann Constant (Ludwig Boltzmann 1844-1906). Temperature $\mathbf{T}$ constitutes a measure of the relative kinetic energy level of the gas. The higher it is the shorter the time between collisions of the gas particles with the boundaries of the system.

In thermodynamic systems, distinctions are made between flow and non-flow systems. For a non-flow system, generally the number of gas units $\mathbf{N}$ is held constant, with pressure $\mathbf{P}$ and volume $\mathbf{V}$ being a function of temperature $\mathbf{T}$. For flow systems, $\mathbf{N}$ becomes a flow of units per period of time, with a corresponding flow of gas volume $\mathbf{V}$ per unit of time (though varying with pressure $\mathbf{P}$ and temperature $\mathbf{T}$. 
Figure 1 Thermodynamic Systems

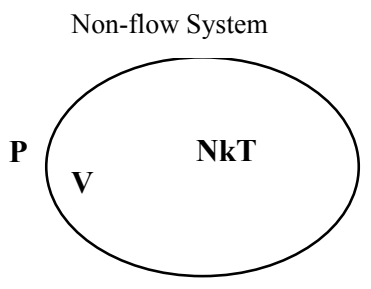

Flow System

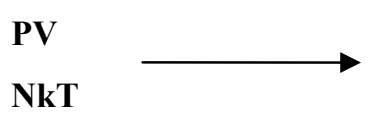

In thermodynamic flow systems it is common to divide both sides of equation (1.1) by $\mathbf{N}$. Thence:

$$
P v=k T
$$

Where $\mathbf{v}=\mathbf{V} / \mathbf{N}$, is the specific volume per molecule. (The more usual thermodynamic presentation of this format is to work in terms of the volume per mass of a very large number of molecules, but we will not confuse the issue here). This arrangement simplifies the kinetics of the analysis of a flow system, as both volume $\mathbf{V}$ and units $\mathbf{N}$ are effectively flow measures per unit of time.

A distinction is also made between open and closed systems. In a closed system, it is possible for energy in the form of heat to cross the system boundary, but matter cannot cross the boundary. In an open system, matter can cross the system boundary.

An equation with a similar structure to equation (1.1) can be constructed for an economic system, involving a number $\mathbf{N}$ of 'carriers or holders of value'. Each carrier or holder embodies a nominal amount of value $\mathbf{k}$, not dependent on price or volume. If a currency this is usually given the numerical value $£ 1, € 1$ etc. The relationship of the system with the outside world is that the value held by carriers or holders of value can be exchanged for goods and services at the boundary of the system at price $\mathbf{P}$ and volume $\mathbf{V}$ over a period of time, according to an Index of Trading Value $\mathbf{T}$ (velocity of circulation) with which they can do this over that period. If they can increase their index of trading value $\mathbf{T}$ over the same period, then the throughput of units goes up. Thus the relationship between the variables is given by the ideal economic equation:

$$
P V=N k T
$$

Figure 2 Economic System

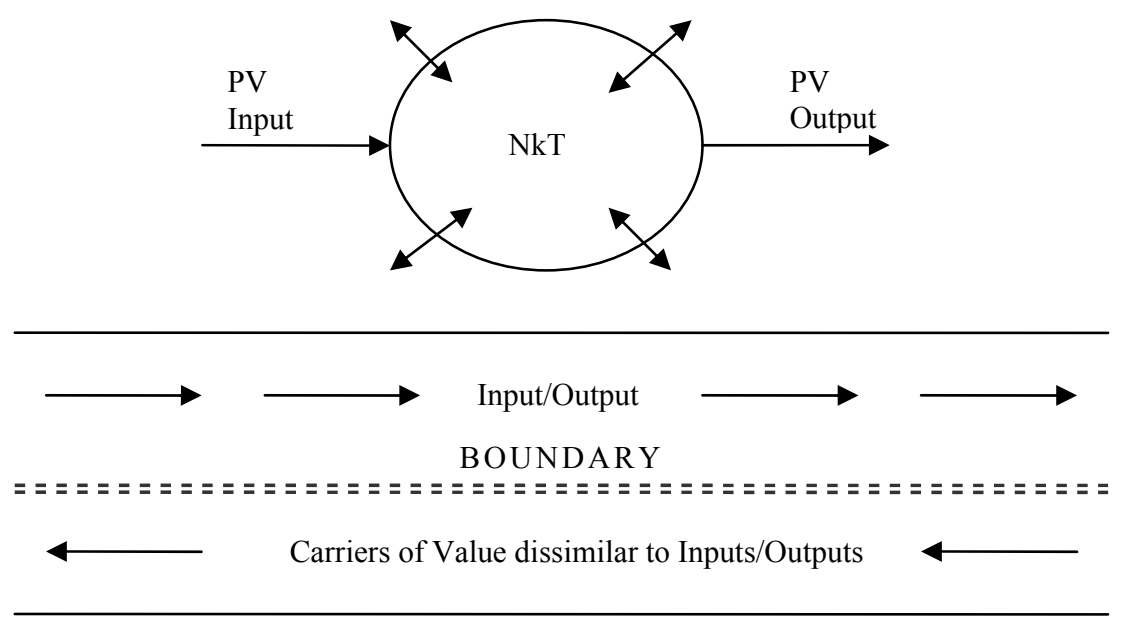

Thus on the left-hand side of equation (1.3) volume throughput $\mathbf{V}$ is in time-flow terms. However, on the right-hand side the time-flow mechanism is transferred to the index of trading value $\mathbf{T}$, with the stock of units $\mathbf{N}$ in circulation remaining relatively constant (subject to expansion of the system). 
An economic system can be conceived as a mix of thermodynamic flow and non-flow systems. Traditional economics mostly tends to view the process as a never ending circular flow process of human activity between production and consumption, played out over time, with ebbs and flows according to a business cycle. While the supply of money in an economy that was not growing or subject to inflation could be viewed as being constant and therefore not flowing, it does however continually have amounts flowing into and out of it, just like a thermodynamic flow system such as a gas turbine with gases from the atmosphere flowing in and exhaust gases flowing out back to the atmosphere. Thus the supply of money might be viewed rather like an atmosphere. There is a difference, however, in that the supply of money and capital reserves are well-defined and have an appreciable effect on the way in which an economy operates. The size of the atmosphere, however, being very large, has no effect on the operation of a gas turbine.

The perception of open or closed economic systems changes with how the boundary is set. A producer trading with customers and suppliers is an open system, whereas an economy that does not trade with any other economies is effectively a closed system. An economist might describe the world as a closed system, but a scientist or engineer would not, as the world receives energy free from the sun, which contributes to the ecological system.

Irrespective of being open or closed, the real size of an economic system (net of inflation) is determined by the flow of throughput volume $\mathbf{V}$ per unit of time.

It should be pointed out that if the carriers of value are different in nature to the inputs/outputs (eg money versus product output) then neither can cross the system boundary and they flow in the opposite direction to each other, though value can be exchanged between them. If, however, the carriers of value and the input/outputs are one and the same (such as a flow of products into a finished stock and then outputted to customers), then there is no boundary and they all flow in the same direction.

The index of trading value $\mathbf{T}$ has similarities with and is related to turnover, cost and added value, though the distinction is that while turnover, cost and added value can be defined in terms of a scale of value, rising or falling in an identical fashion to our index of trading value $\mathbf{T}$, they are not technically the same as $\mathbf{T}$, unless they are divided through by $\mathbf{N k}$.

The index $\mathbf{T}$ is most readily equated to the Velocity of Circulation of a currency, relating output value $\mathbf{P V}$ to money stock $\mathbf{N}$, though there is no reason why it should not be compared with the velocity of other items of exchange. For example, depreciation and profit (part of output PV) can be related respectively to producer capital stock and capital employed (larger entities than money stock $\mathbf{N}$ ) via the rate of return. The only difference is that the index $\mathbf{T}$ for a money stock might be $1-2$ times per annum, whereas for a capital situation $\mathbf{T}$ becomes a rate of return with a turnover of perhaps 0.02-0.10 times per annum. 
The original paper of 2007 described a number of stock models. Chief among these are industrial capital stocks, labour and resource stocks. To these can be added output, consumer and waste stocks. These can call be joined together to form an overall economic flow system, served by a monetary system.

Figure 3 Simplified Factor Conversion Process

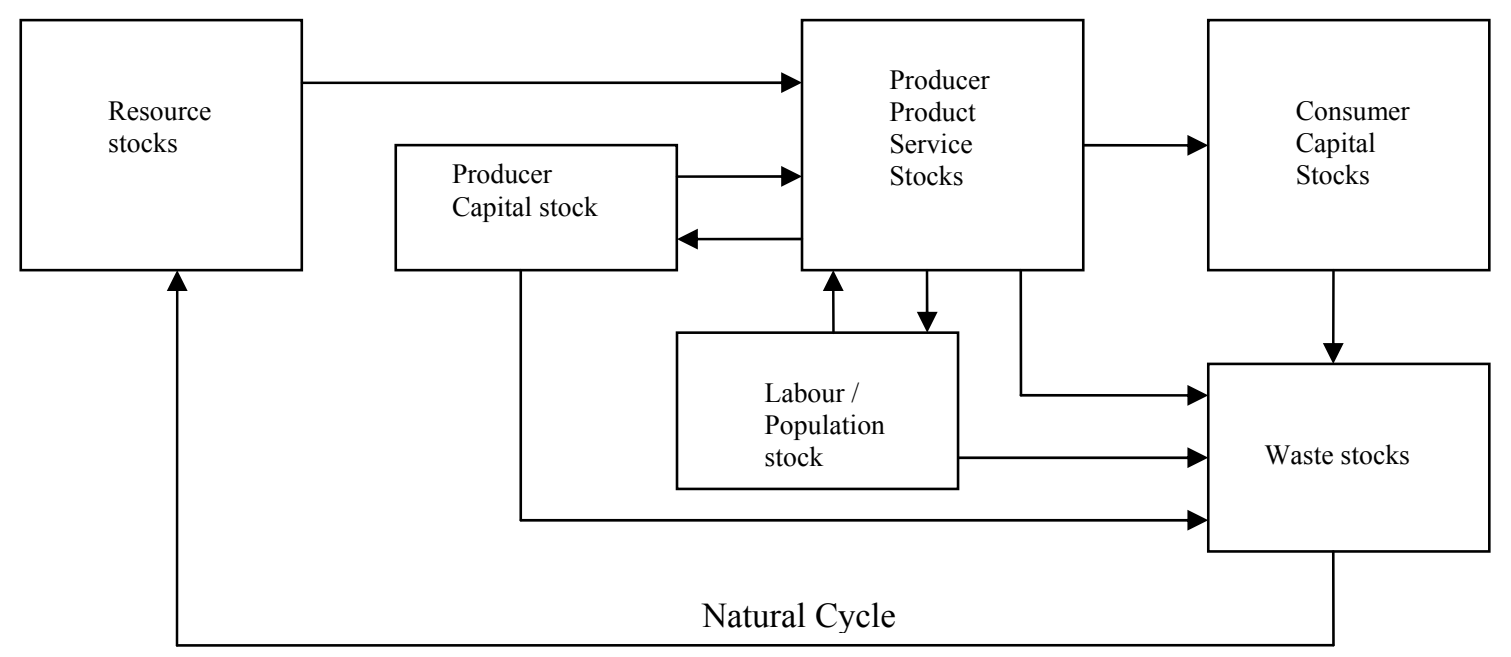

Further chains in the reaction may also be supposed, of goods and services being circulated to investment in producer capital stock, consumption to rebuild labour stock (via a long cycle of births and education), and to consumer stocks of varying length, from short term (consumer non-durables) through to durable goods such as housing (a form of capital stock). Expenditure on repairs and maintenance and health services may also be considered as investment - to maintain the lifetime of labour, capital and consumer stocks. A further chain occurs as consumer stocks themselves become waste stocks or are recycled (in part) via nature. There are significant time lags in the above processes.

\subsection{General Stock Model}

A model can be constructed, that follows the format of equation (1.3), which describes the process for a general stock. Imagine a stock composed of $\mathbf{N}_{\mathbf{Z}}$ units of a good $\mathbf{Z}$, each having a nominal value $\mathbf{k}_{\mathbf{Z}}$ per unit, independently measured and not dependent upon supply/demand. Each unit of stock has a normal lifetime $\mathbf{t}_{\mathbf{L}}$. The stock of $\mathbf{N}_{\mathbf{Z}}$ units has a volume throughput rate of $\mathbf{V}_{\mathbf{Z}}$, equal to $\mathbf{n}_{\mathbf{Z}}$ units of stock per transaction time $\mathbf{t}_{\mathbf{T}}$. The transaction time $\mathbf{t}_{\mathbf{T}}$ is commonly regarded as a year or other time denomination. If input and output volumes change with respect to each other, then the stock of units can rise or fall.

Figure 4 Simple Stock Model

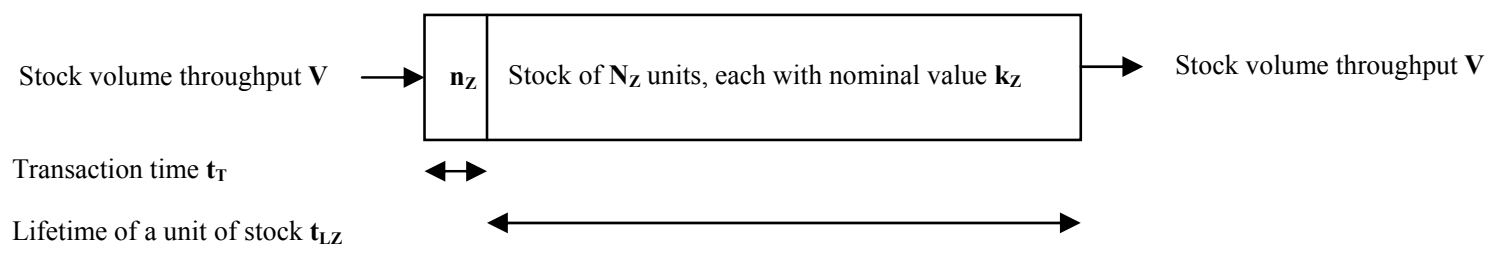

Thus total volume throughput $\mathbf{V}_{\mathbf{Z}}$ per unit of time is equal to:

$$
V_{Z}=\frac{n_{Z}}{t_{T}}=\frac{N_{Z}}{t_{L Z}}=v_{Z} N_{Z}
$$

Where $\mathbf{v}_{\mathbf{Z}}=\left(\mathbf{1} / \mathbf{t}_{\mathrm{LZ}}\right)$ is the throughput rate of a unit of stock per unit of time, and is inversely proportional to a function of the lifetime of a unit of stock. Hence by cross multiplying we have an expression for the volume stock quantity per transaction quantity, being a function of the lifetime $\mathbf{t}_{\mathrm{LZ}}$ divided by the transaction time $\mathbf{t}_{\mathbf{T}}$ : 


$$
\omega_{Z}=f_{1}\left(\frac{N_{Z}}{n_{Z}}\right)=f_{1}\left(\frac{t_{L Z}}{t_{T}}\right)
$$

And the volume for 1 transaction may given by:

$$
n_{Z}=f_{2}\left(\frac{N_{Z}}{\omega_{Z}}\right) \text {. }
$$

There are arguments as to the nature of the lifetime of a stock. Some stocks maintain their productive value all the way through their lifetime, until consumed. Others such as human labour and capital stocks can lose their productive value with time, though repair and maintenance and health expenditure can reduce this loss. Humans do however retire from work and capital stock depreciates, and economic output can go up and down. Thus the profile of stocks leaving the process may differ from the profile of those joining. For resource stocks, the throughput rate $\mathbf{v}_{\mathbf{Z}}$ is dependent upon renewability, economic and technology factors. Oil field production rates can grow, peak and decline. Bank notes and coin have a high throughput rate and a corresponding short lifetime.

Each unit of stock has a nominal inherent productive content $\mathbf{k}_{\mathbf{Z}}$ measured in terms of what it can do, or pass on when it is consumed. Thus, for example, fuels and minerals will have an inherent exergy value with reference to the environment [Ayres, R. Warr, B. (2003)], and a food source will have vitamin and energy content.

It is more difficult to imagine the productive content of human labour, particularly in developed economies. Labour power has progressed from being primarily a workhorse, inputting energy to produce output, to being a factor supplying mostly information and management to the process. Even construction and farm workers often now use machines driven by energy sources in their work to produce output (rather than animal and human power), and their role now involves inputting information via hand controls. This assumes of course that a source of energy will always be there in the future to fuel this work. The economic process, however, values labour power by what it is paid in money terms, which is reflected in the price or wage of manpower. Thus the valuation becomes a subjective assessment by humans as to the contribution they make to the production process and what they can reasonably acquire to their benefit. This is not to say necessarily that this is also to the benefit of the ecosystem.

For resource stocks, from a thermodynamic perspective, the value to be abstracted or harvested from renewable or nonrenewable resources technically exists already - examples oil and iron ore. This inherent value is called exergy, and measures the relative value distance from the environmental average. Thus a high grade iron ore would have a greater exergy than a low grade iron ore, and oil from a gusher oilwell might have more exergy than tarsand that requires significant energy input to make it useable in the market. Humankind just abstracts the resource value and disperses it to its benefit, potentially reducing the value of some of what is left, sometimes without much thought to the environmental and ecological consequences of doing so. In thermodynamic terms the process involves an irreversible increase in entropy and consumption of exergy. Schneider \& Kay [Schneider \& Kay (1992), (1995)] state that life can be viewed as a far-from-equilibrium, dissipative structure, that maintains its local level of organisation at the expense of producing entropy in the environment. Successful species are those that funnel energy into their own production and reproduction.

While exergy may represent the inherent productive content than can be abstracted from a resource, economics calculates the cost of the resource as being made up chiefly of capital stock depreciation, labour and transport costs. While, for intermediate economic and industrial concerns, resource and inventory costs clearly constitute a significant part of the process, from an economic perspective ultimately these costs are defined only in terms of the value of labour and capital stock consumed in acquiring them, whether from a local producer or imported from another country. National accounts measure economic activity in terms of wages and profits/rent/interest, or as investment and consumer/government expenditure with adjustments for exports/imports. While some imports such as oil may be regarded as resources, these are valued by their suppliers in terms of the capital and labour stock costs required to produce and transport them. Transport also involves labour and capital stock costs and energy costs, and energy supply used up in transport in turn involves labour and capital stock costs, and capital stock production also involves labour costs - and so ad infinitum. Ultimately, resources are economically free to humankind - nature does not sell them to us. Economists make the assumption that humankind has effectively commandeered them and is distributing them to itself, according to a perceived self-interest benefit and the labour and capital stock cost of acquiring/producing them. While such a process may not be in principle different from say a bird building a nest, commandeering twigs, moss and mud in the process, the scale involved is of course much greater. Thus there is a fundamental difference between economic and thermodynamic perspectives. 
A point to state here with respect to the nominal value $\mathbf{k}$, is that we are not ascribing here a utility value, but a productive content. Utility is a notion invented by economists to explain the paradox of say diamonds having much higher values than can be explained in terms of the cost of their production or their usefulness, compared to say water. In the original paper [Bryant, J. (2007)], the notion of marginal utility was replace by marginal entropic value, being a function of change in entropy. Thus, for example, a diamond can be worth more or less, and priced accordingly, depending upon the economic entropy that consumers wish to attach to it, benefit from and later pass on to others. On a desert island, such entropic value can be lost completely.

With respect to capital stocks, depreciation is a form of productive content of producer and consumer capital stocks that is used up as production or consumption progresses. It is or can be replaced by new investment, which is made up of material and information content, designed by human ingenuity and put together in the production process by humans and machines driven by energy. Clearly a definition of the productive content of one item of capital stock, let alone the millions of different forms it takes, from a power station to a pin, is complex. As with other parts of the economic process, economics get around this by defining capital stock in money terms, that is, the money paid for a new investment, whatever form or size it takes and its productive content. Thus, in money terms, when looking at the process from whence the new investment came, it should be recognised that some of this value is made up of wages paid to the humans who constructed the capital stock investment, and the rest from resource costs and consumption of capital equipment, which in turn, taking the process one step further back, come from other processes also incorporating wage costs; even the owner of an oil field charges a wage or dividend for his/her trouble for the energy transported to power the capital equipment. Thus, in the ultimate, all capital stock models are effectively calculated on a basis of accumulated wage costs. This is not to deny that real value in terms of productive content and exergy is abstracted from the capital stock as it is used up. It is just that economics approaches the valuation of that consumption of productive content in a different manner.

Returning to our development, and excluding for the moment monetary aspects, equation (1.3) for a stock could be written as:

$$
P_{Z} V_{Z}=N_{Z} k_{Z} T_{Z}
$$

which expresses the price and volume flow of inputs and outputs in terms of the number of stock units $\mathbf{N}_{\mathbf{Z}}$, the nominal inherent productive content $\mathbf{k}_{\mathbf{Z}}$ per unit, and the index of trading value $\mathbf{T}_{\mathbf{Z}}$. It will be noted here that everything on both sides of the equation is expressed in terms of the stock $\mathbf{Z}$. To compare the stock with other different stocks, economics introduces the concept of money and equation (2.5) becomes:

$$
P_{M} V_{Z}=N_{M} k_{M} T_{M}
$$

Where all factors except volume throughput $\mathbf{V}_{\mathbf{Z}}$ of stock $\mathbf{Z}$ are instead expressed in money terms, and where $\mathbf{T}_{\mathbf{M}}$ is the index of trading value (velocity of circulation) of the money stock. It should be noted that the two stocks are only comparable through the interface of input and output, and that they flow in the opposite direction to each other.

By combining equations (2.5 and (2.6) we have:

$$
\left(\frac{P_{Z}}{P_{M}}\right)=\left(\frac{N_{Z}}{N_{M}}\right)\left(\frac{k_{Z}}{k_{M}}\right)\left(\frac{T_{Z}}{T_{M}}\right)
$$

But since both currency $\mathbf{k}_{\mathbf{M}}$ and stock units $\mathbf{k}_{\mathbf{Z}}$ are defined as 1 ( $£ 1,1$ car etc), then the equation reduces to:

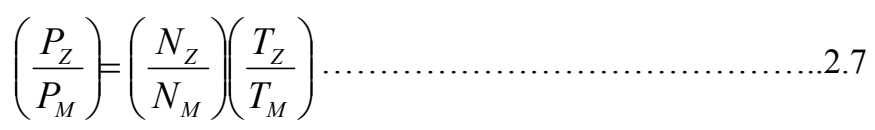

Which expresses the relative prices in terms of the relative stocks and indices of trading value (velocities of circulation). 
To give a simple example: suppose stock $\mathbf{Z}$ of a small business was composed of two PC computers each valued at 1 computer unit of productive content (if such were a standard), with no inflation or utility/entropy gain. Thus price $\mathbf{P}_{\mathbf{Z}}$ of output is equal to $\mathbf{k}_{\mathbf{Z}}$, which is equal to 1 . The computers lose value at $50 \%$ per annum straight-line depreciation and are replaced every 2 years. Thus the right hand side of the equation (2.5) becomes $2 \times 1 \times 0.5=1.0_{\mathrm{Z}}$, which also equals the left hand side - the depreciation of the computers. Thus the small firm has to buy one new computer each year. We now choose to value the computer in terms of currency $\mathbf{M}$. We suppose that 1 computer unit is equal to 1,000 $\mathbf{M}$ units of currency. Thus the left hand side of equation (2.6) becomes $1,000_{\mathrm{M}} \times 1.0_{\mathbf{Z}}=1,000_{\mathbf{M}}$. It is a matter of practicality as to what funding a small business might have, either in terms of positive cash reserves in a bank or of borrowed funds. If the small business kept reserves of 6 months trading, not unlike the money supply of an economy, then the amount of reserves earmarked for computer replacement would be given by:

$$
1000_{M}=N_{M} \times 1_{M} \times 2
$$

Thence the nominal stock value of currency $\left(\mathbf{N}_{\mathbf{M}} \mathbf{k}_{\mathbf{M}}\right)$ funding computer replacement would be $500_{\mathbf{M}}$, to which would be added other amounts to fund the rest of the business.

\subsection{Monetary Stock Model}

A thermodynamic model of a monetary system joining all the sectors was proposed in the original paper. It has the form:

$$
P V=N k T
$$

Where $\mathbf{P}$ is the overall price index of an economy, $\mathbf{V}$ is output per annum at constant prices, $\mathbf{N}$ is the supply of money (MO, M3, M4 etc), $\mathbf{k}$ is a monetary constant ( $£ 1, € 1$ etc) and $\mathbf{T}$ is the velocity of circulation. In this model, output of products and services [the left-hand side of equation (2.9)] flow in one direction, and money [the right-hand side of the equation] flows in the opposite direction (the reverse of the general stock form).

Figure 5 Monetary model

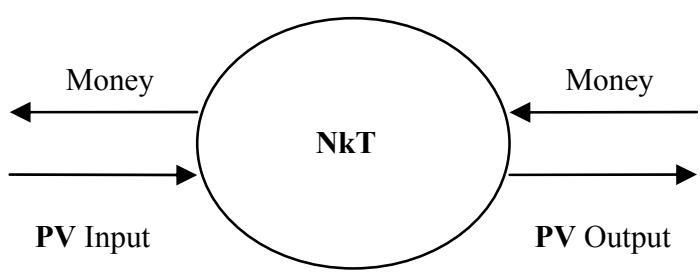

It is intuitively obvious that a higher level of trading index (velocity of circulation) $\mathbf{T}$ is associated with a shorter-lifetime of money. Electronic money has a very short lifetime, whereas commercial paper and bonds (included in M3) have maturity up to 5 years). Referring back to the gas model, a higher level of temperature is associated with a higher kinetic energy, which is a function of the average velocity of molecules, and hence inversely proportional to a function of the lifetime between collisions of a molecule with the boundaries of a system.

In analysing a monetary system, initial thoughts centred on shortening equation (2.8), to one that looked similar to equation (1.2), with a specific output per unit of money stock $\mathbf{v}=\mathbf{V} / \mathbf{N}$, with the thought that this might measure improvements in volume throughput of money stock. This did not however allow for the fact that price rises in output resulting in inflation can effectively devalue the nominal value $\mathbf{k}$ of the currency unit. Thus, in a money system, the number of units $\mathbf{N}$ represents the number of nominal values $\mathbf{k}$, not a fixed value, and we are thus back to the central problem of comparative nature of the discipline of economics. Despite this, modern economies choose to base values in the system on a currency, and rely on measures of price change per unit of output volume to determine the extent to which a currency holds its value.

Consequently thoughts have turned to expressing equation (2.8) as either:

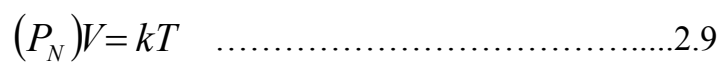

Where $\mathbf{P}_{\mathbf{N}}=\mathbf{P} / \mathbf{N}$, or

Where $\mathbf{N}_{\mathbf{P}}=\mathbf{N} / \mathbf{P}$.

$$
P V=N_{P} k T .
$$


An earlier paper was produced in 2008 [Bryant, J. (2008)] to give empirical context to the above revised equations, and which were illustrated by statistical analysis of quarterly data of GDP, money supply, inflation and interest rates over a period of about 40 years for each of the UK and USA economies. The paper derived relationships between interest, entropy and the yield curve.

\subsection{Labour Sector}

Human labour activity constitutes a major input to all economic systems. As noted earlier, the nature of human labour has changed from historical past, when it provided essentially only 'man-power' (with the assistance of domesticated animal power). In the modern economy much power is now provided by machines which consume energy, some of which are nonrenewable in the scale of human existence, carrying unfortunate by-products such as $\mathrm{CO}_{2}$ production or nuclear waste. Human labour has graduated somewhat therefore towards providing, utilising and managing information in support of production processes. Without a source of energy to fuel the machines, the modern economy would have difficulty in operating and would almost certainly have to change in form.

Reverting back to our discourse, as production of output progresses over time, a proportion of the labour force that provided the 'man-power' and 'information-power' is consumed (retired). This equates to the throughput volume $\mathbf{V}$ as per the general stock model set out at section 2.1. New units of labour will eventually enter the system to offset this reduction, via the births/upbringing cycle of population, provided that sufficient fruits of output are directed towards the costs of births/upbringing. Demand will also influence factors such as recruitment levels, redundancies, unemployment and early retirement, which affect total labour requirements. It is of course quite reasonable to expand the model by reference to links with changes in population cycle of births, education and retirement, though that is set aside here.

In labour terms equations (2.2) and (2.5) can be combined as expressed as follows:

$$
P_{L} V_{L}=P_{L}\left(v_{L} N_{L}\right)=N_{L} k_{L} T_{L}
$$

Where $\mathbf{P}_{\mathbf{L}}$ is the effective unit price of labour throughput, $\mathbf{V}_{\mathbf{L}}$ is the labour volume throughput, $\mathbf{v}_{\mathbf{L}}$ is the volume throughput rate of labour stock per unit of labour stock per unit of time, $\mathbf{N}_{\mathbf{L}}$ is the total number of labour units existing, $\mathbf{k}_{\mathbf{L}}$ is the nominal value or productive content that a unit of labour can provide over a lifetime, and $\mathbf{T}_{\mathbf{L}}$ is the index of trading/velocity of throughput of labour. Thus the left-hand side of the equation represents the labour cost consumed or generated per unit of time, and the right-hand side the effective turnover of the labour productive content per unit of time.

In economic analysis it is common to write labour cost as wage rate $\mathbf{w}_{\mathbf{L}}$ paid per unit of time multiplied by total labour units $\mathbf{N}_{\mathbf{L}}$, thus $\mathbf{w}_{\mathbf{L}} \mathbf{N}_{\mathbf{L}}$. Substituting this into equation (2.11), then the left-hand and right hand sides become:

$$
P_{L} V_{L}=P_{L}\left(v_{L} N_{L}\right)=w_{L} N_{L}=N_{L} k_{L} T_{L}
$$

Where $\mathbf{w}_{\mathbf{L}}$, the wage rate per unit of time, is equal to $\mathbf{P}_{\mathbf{L}}$, the wage cost per unit of labour throughput, multiplied by $\mathbf{v}_{\mathbf{L}}$, the volume throughput rate of labour stock per unit of labour stock per unit of time.

However, as set out in the general stock model for our economic system and postulated at equation (2.6), there exists an equal and opposite flow of money to labour output (cost) and we can therefore write as an alternative:

$$
w_{M} N_{L}=N_{M} k_{M} T_{M}
$$

Where the wage rate $\mathbf{w}_{\mathbf{M}}$ per unit of time is instead measured in terms of money, $\mathbf{N}_{\mathbf{M}}$ is the supply of money to the labour process, $\mathbf{k}_{\mathbf{M}}$ is the nominal value of a money unit (usually $£ 1, € \$$ etc), and $\mathbf{T}_{\mathbf{M}}$ the velocity of circulation of money to the labour sector. Thence, because $\mathbf{k}_{\mathbf{M}}$ and $\mathbf{k}_{\mathbf{L}}$ are nominally expressed as 1, we can write:

$$
\left(\frac{w_{L}}{w_{M}}\right)=\left(\frac{N_{L}}{N_{M}}\right)\left(\frac{T_{L}}{T_{M}}\right)
$$

This provides a means of measuring and reconciling the lifetime nominal wage rate $\mathbf{w}_{\mathbf{L}}$ with the nominal value in terms of money units $\mathbf{w}_{\mathbf{M}}$, though of course this still does not obviate the problem of the comparative nature of economics. While it is 
the accepted norm to measure wages and prices by reference to units of money, this does not negate the principle of the underlying lifetime value or productive content of a unit of labour - however that may be measured.

It is accepted also that the labour market is a good deal more complex than the above simplistic presentation, particularly in respect of the distribution of earnings according to nominal values to be attached to different types of labour, from manual up to professional, the age and educational distributions, lifetime in active work and differences between individual industrial and world markets.

\subsection{Capital Stock Sector}

Equations describing capital stock can be set out in a similar manner to the general stock model. In capital stock throughput terms equation (1.3) can be written as:

$$
P_{K} V_{K}=P_{K}\left(v_{K} N_{K}\right)=N_{K} k_{K} T_{K}
$$

Where $\mathbf{P}_{\mathbf{K}}$ is the effective price/cost/value of a unit of capital stock throughput, $\mathbf{V}_{\mathbf{K}}$ is the volume throughput per unit of time of capital stock units (not value), $\mathbf{N}_{\mathbf{K}}$ is the total number of capital stock units (not value), $\mathbf{v}_{\mathbf{K}}$ is the volume throughput rate of capital stock per unit of capital stock per unit of time, $\mathbf{k}_{\mathbf{K}}$ is the nominal lifetime value of a unit of capital stock (i.e. not varying), and $\mathbf{T}_{\mathbf{K}}$ is the index of trading value (velocity) of capital stock (not necessarily the same as the volume throughput rate $\mathbf{v})$. The volume throughput rate $\mathbf{v}_{\mathbf{K}}$ is most readily associated with the depreciation rate of a capital stock, with differences between inputs and outputs to the capital stock being associated with residual profits/losses and increases/decreases in capital investment over depreciation. The left-hand side of the equation therefore represents flow to and from capital stock, and the right-hand side nominal capital stock value multiplied by an index of trading value (velocity of circulation) $\mathbf{T}_{\mathbf{K}}$.

In a similar fashion to the general stock model, a reverse monetary flow equation can be set out, but instead of relating depreciation to a money supply, such as M3 or M4, it is simpler to relate it to total capital employed in fixed assets. Thence equation (2.15) remains essentially the same, and no money subscript $\mathbf{M}$ is needed, except to note that all values are expressed in money units rather that units of fixed capital.

Now by re-arranging equation (2.15) we can write:

$$
T_{K}=\left[\frac{P_{K}\left(v_{K} N_{K}\right)}{k_{K} N_{K}}\right]=\left(\frac{P_{K}}{k_{K}}\right) v_{K} \ldots \ldots \ldots \ldots \ldots \ldots \ldots \ldots \ldots \ldots \ldots \ldots \ldots \ldots \ldots \ldots \ldots . . .16
$$

Relating the index of trading value $\mathbf{T}_{\mathbf{K}}$ to the depreciation/investment/profit rate $\mathbf{v}_{\mathbf{K}}$ multiplied by a ratio of the price of capital stock divided by the nominal value of capital stock. Thus the index of trading value $\mathbf{T}_{\mathbf{K}}$ effectively represents the per annum yield of an investment. This relationship was explored in more depth in the earlier paper of 2008 concerning money [Bryant, J. (2008)].

\subsection{Resource Stock Sector}

Returning to the thesis, in a similar manner to labour and capital stock, equations can be constructed describing a resource or stock R. Resources and stocks can occur at many stages in the economic process - examples: oil reserves, inventories before or after production. In resource stock throughput terms equation (1.3) can be written as:

$$
P_{R} V_{R}=P_{R}\left(v_{R} N_{R}\right)=N_{R} k_{R} T_{R}
$$

Where $\mathbf{P}_{\mathbf{R}}$ is the effective price/cost/value of a unit of resource stock throughput, $\mathbf{V}_{\mathbf{R}}$ is the volume of resource stock unit throughput (not value) per unit of time, $\mathbf{N}_{\mathbf{R}}$ is the total number of resource stock units (not value), $\mathbf{v}_{\mathbf{R}}$ is the volume rate of resource stock unit throughput per unit of resource stock per unit of time (a volume depletion, extraction or addition rate), $\mathbf{k}_{\mathbf{R}}$ is the nominal lifetime value of a unit of resource stock (i.e. not varying), and $\mathbf{T}_{\mathbf{R}}$ is the index of trading value (or velocity) of resource stock (not necessarily the same as the volume throughput rate v). 
Resource stocks come in two broad types, renewable and non-renewable. Renewable resource stocks are those which have both an input and an output. Clearly a goods-in inventory would fit this model, as would wind and solar generated energy and fish stocks, though the latter may rely on nature rather than humankind to provide the input. Non-renewable resources are those that have little or no input, and are only defined by their extraction or consumption rates. Oil and gas reserves fit this model, though even here humankind endeavours to prospect for new reserves, sometimes with much success.

From equation (2.17), the index of trading value is expressed as:

$$
T_{R}=\left(\frac{P_{R}}{k_{R}}\right) v
$$

Thus the index of trading value depends not only on the depletion/extraction/addition rate, but on the price of a resource compared to its nominal value.

In identical manner as before we can express resource usage in terms of opposite flows of money associated with it:

$$
P_{M} V_{R}=P_{M}\left(v_{R} N_{R}\right)=N_{M} k_{M} T_{M}
$$

In economic terms, however, the above money equation will only relate to resources coming from or proceeding to destinations outside the system, such as imports and exports, and purchases and sales. As explained at section 2.1 of this paper concerning the general stock model, while resources clearly have productive content, measured in terms of exergy or other inherent value, they have nil economic value except in relation to the human labour and capital stock money values attached to them. The thermodynamic consequences of this point will be developed later in this paper. Nevertheless, when considering a specific economic system, it is pertinent to consider resource and product flows to and from a system, and how they relate to money stocks.

\subsection{Consumer Capital Stocks}

The structure of consumer capital stocks (cars, houses etc) is similar in nature to resource capital stocks, and no additional equations are required. The size of stock levels depends upon demand and saturation, and input and output throughput is influenced by input new build rates, repair and maintenance expenditure, and scrap/depreciation/obsolescence rates of old stock.

\subsection{Environment/Waste Sector}

This sector can be thought of primarily as a resource sector in reverse, though in many cases economic costs have not hitherto been considered. Examples of costs include nuclear waste disposal, waste recycling and $\mathrm{CO}_{2}$ sequestration. While clearly throughput additions to a waste sector can be imagined, consumption relies on further recycling, perhaps via the natural cycle. The net cost to an economic system may therefore be viewed as the extent to which additions can be minimised or consumption can be increased via re-cycling.

In resource stock throughput terms equation (1.3) can be written as:

$$
P_{D} V_{D}=P_{D}\left(v_{D} N_{D}\right)=N_{D} k_{D} T_{D}
$$

Where $\mathbf{P}_{\mathbf{D}}$ is the effective cost of a unit of waste stock throughput, $\mathbf{V}_{\mathbf{D}}$ is the volume of waste stock unit throughput (not value) per unit of time, $\mathbf{N}_{\mathbf{D}}$ is the total number of waste stock units (not value), $\mathbf{v}_{\mathbf{D}}$ is the volume rate of waste stock unit throughput per unit of waste stock per unit of time, $\mathbf{k}_{\mathbf{R}}$ is the nominal lifetime negative productive content or value of a unit of waste stock (i.e. not varying), and $\mathbf{T}_{\mathbf{D}}$ is the index of trading cost/velocity of waste stock (not necessarily the same as the volume throughput rate v). Where an economic system considers the impact of the environment/waste sector, equal and opposite flows of money can be supposed for such costs. 
Waste stocks come in three broad types, recyclable, non-recyclable and polluting. Recyclable waste stocks are those that can be returned to some degree as a resource (eg scrap metal), but at an economic cost, or by the processes of nature. Nonrecyclable waste stocks are those that have to be buried or rendered inanimate and no longer a part of the environment, also at a cost. Polluting waste stocks are those that have no economic cost, but degrade resources or the environment in some manner.

\section{System Reaction}

The thermodynamic theory developed in the original paper to show the dynamic processes in an economic system is based on the Le Chatelier Principle which states: "If a change occurs in one of the factors under which a system is equilibrium, then the system will tend to adjust itself so as to annul as far as possible the effects of that change". It is not asserted that a system will attain equilibrium, only that it will continually seek to proceed to such a position. In fact the system will not work without being in a state of disequilibrium.

First, the analysis is restricted to an economic system involving a specified, fixed process. By this is meant that, for example, to produce a product, specified amounts of capital stock (depreciation), labour (proportion of lifetime output) and resources/materials are required, and no other combination, and which are brought together under a specified production process. In gas/chemical reactions such fixed arrangements are normal, there being only one configuration of inputs and outputs; for example, two molecules of carbon monoxide combust with one molecule of oxygen to form two molecules of carbon dioxide. There is no other combination. Thus in an economic system with an inexact mixture, if a reaction proceeds so that one input is completely used up, there are likely to be some other inputs left over. If there is a scarcity such that a substitute is found, then the substitute is another product made by another process/system, and outside the dynamics of the system under analysis. Likewise if a different mix of inputs can be engineered by investment in plant and management, we are again discussing another system. In this initial analysis it is only the dynamics of a fixed system that are being examined, and not feedback mechanisms to change the choice or structure of a system.

There is therefore a difference between human and gas/chemical systems, in that humankind can continually modify its economic system in order to change the objectives and benefits - a complex feedback mechanism. A further factor to consider is that the inputs and outputs in human systems are all very different in nature, though this does not stop the process of combining them together. This occurs of course through the medium of money, which travels in the opposite direction to product inputs and outputs, as set out earlier.

Imagine a specific production process, whereby to form $\mathbf{x}$ units of a particular output product stock $\mathbf{G}$, requires consumption of $\mathbf{a}$ units of capital stock $\mathbf{K}, \mathbf{b}$ units of labour stock $\mathbf{L}$, and $\mathbf{c}$ units of resource(s) stock $\mathbf{R}$. $\mathbf{y}$ units of residue stock $\mathbf{D}$ are also produced (assuming that the cost of waste disposal is costed into the equation). The factors $\mathrm{a}, \mathrm{b}, \mathrm{c}, \mathrm{x}$ and $\mathrm{y}$ are fixed by the nature of the specific process considered - human-hours, energy and electricity requirements, nuts $\&$ bolts from a resource stock to make up a specific product, irrespective of time. They indicate the relative amounts that are required to make up a product. Some processes, such as oil production and power generation, are capital intensive, requiring large amounts of capital stock relative to manpower. Other processes are not capital intensive. We could write:

$$
a K+b L+c R \Leftrightarrow x G+y D
$$

Where the double arrow signifies that the process is not necessarily a complete one; it depends upon the actual relative concentrations of each, and the position of the equilibrium point, which may vary. Thus if output stock $\mathbf{G}$ cannot be passed on to buyers from another system, if there are shortages in financing or labour, or a scarcity of materials from a late delivered stock or a resource depletion, or capital plant cannot be operated at higher level, then there will be a reduced economic incentive to promote the forward path in the system under consideration. We could simplify the above equation by dividing through by $\mathbf{x}$, and substitute $\boldsymbol{\alpha}=\mathbf{a} / \mathbf{x}, \boldsymbol{\beta}=\mathbf{b} / \mathbf{x}, \boldsymbol{\delta}=\mathbf{c} / \mathbf{x}$ and $\boldsymbol{\rho}=\mathbf{y} / \mathbf{x}$. Thus:

$$
\alpha K+\beta L+\delta R \Leftrightarrow G+\rho D
$$

In economics, specifically the Cobb Douglas production function [Cobb, C. W, Douglas, P.H, (1928)], the factors $\boldsymbol{\alpha}, \boldsymbol{\beta}$ etc are described as elasticity coefficients, and in equation (3.2) these would signify:

$$
\begin{array}{ll}
\alpha+\beta+\delta-\rho<1 & \text { Decreasing returns to scale } \\
\alpha+\beta+\delta-\rho=1 & \text { Constant returns to scale } \\
\alpha+\beta+\delta-\rho>1 & \text { Increasing returns to scale }
\end{array}
$$


There is, however, a blurring of compatibility here, in that each factor is different to the others, united only by comparison to units of money. To reduce the incompatibility effect, economics sometimes creates an index for each factor $\mathbf{K} / \mathbf{K}_{\mathbf{0}}, \mathbf{L} / \mathbf{L}_{\mathbf{0}}$, etc where the subscript $\mathbf{0}$ represent a reference amount at a previous point in time. Thus each index can measure the growth of each factor over time. The drawback of this method is that each factor is automatically given the same value of 1 at the start point, though they may have very different inputs in reality. This is compensated to some extent by the different elastic indices attached to each factor. Nevertheless, to give a simple example of the problem: 500 Egyptians using a piece of capital stock called a rope can haul a large block of stone. The same operation might be done a high horsepower tractor operated by one man.

Returning to our discourse, imagine a closed system containing some arbitrary amounts of reactants of capital plant, labour and resources, depicted by the dotted lines in figure 6, which have a motive (cash reserves to be used up, and a potential for cash receipts) to combine together to form a product, depicted by the solid line. Initially the reaction rate is fast, as the concentrations of the three factors of production reduce and with the concentration of product increasing, but, as the process proceeds, with more and more product being formed and less and less input remaining (and without replacement of cash reserves via cash receipts), the incentive to continue reduces and the reaction progressively slows down to an equilibrium point.

Figure 6 Production Process

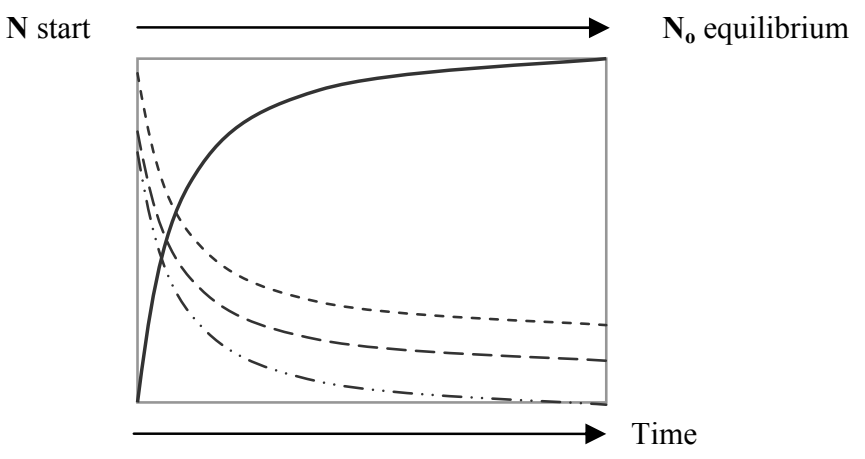

Now we imagine that the product formed to the equilibrium point is taken away, in return for money/sales turnover input, which reduces the product concentration in the closed system back down to zero. The process is brought back to its original position if the money input is used to replenish money reserves and purchase further units of inputs. The production momentum is then able to recommence. Thus a production system can effectively be constructed from a series of cycles, as in figure 7, with the dotted curve depicting resource usage, and the solid curve depicting product output.

Figure 7 Production Cycle

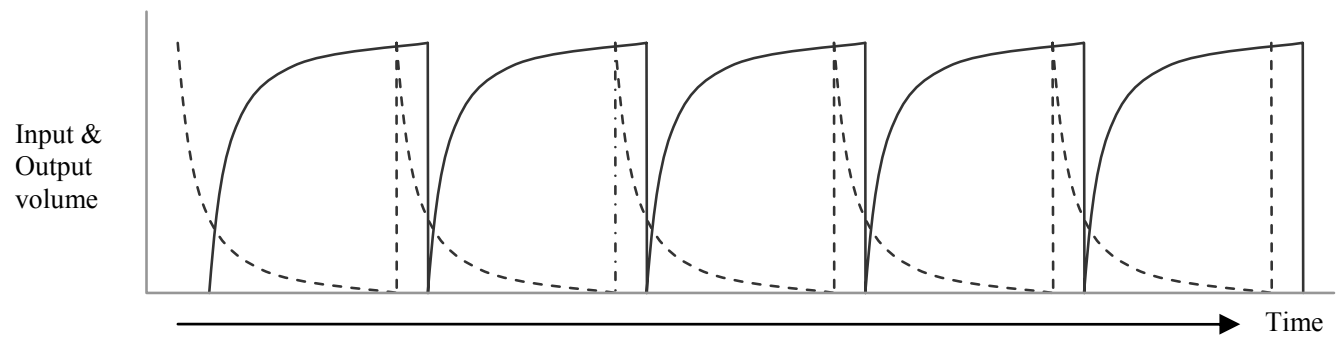

For an instantaneous production system, one might imagine that the inputs and outputs flow could take place at a virtually constant rate, with the curved lines becoming straight - a triangular picture. This might be particularly prevalent if observers and managers of the system were fully confident of the continuity of the outcome. The reality of the system, however, is that buyers and sellers relate to outside systems that do not always run in a perfect synchronous manner with each other. Thus ebbs and flows of demand will change the shape of the curves.

Before proceeding with the thermodynamic analysis, an important point should be made. Traditional economics tends to consider the factors of production as existing continually with production emanating from them. Moreover, the standard Cobb Douglas equation only has capital and labour on the left hand side and no resources. Thus output just 'happens' or is 'created'. The economist tends to take for granted that resources are used up in the process. As stated earlier their inherent values are deemed 'free', and consideration is given only to their capital and labour costs. 
The physicist, on the other hand would regard this assumption as contravening the Laws of Thermodynamics. Heat can only flow from a hotter body to a cooler body. Thus the items providing the heat and energy input (technically exergy in relation to an environment) are the resources, labour consumption and capital depreciation, which in turn create product, some of which is eventually returned as labour production (births) and capital stock production (investment). No money is involved in this conversion, though it does flow in the opposite direction, and act as a medium of exchange. Thus, in the limit, if both labour and capital stocks are regenerating themselves or growing, the process flow arises from a consumption of resource exergy. Thus only resources can provide the net energy for the human system to maintain itself or expand. The proverbial ant heap does not grow of its own, but by the consumption of accessible resources and nutrients.

In the original paper of 2007 [Bryant, J.( 2007)] in order to represent the potential work released by the consumption of capital, labour and resources and converted into product, resort was made to a thermodynamic property known as the Helmholtz Free Energy function F [German physicist Hermann von Helmholtz 1821 - 1894]. This function is a common concept in thermodynamic analysis of chemical reactions, and expresses the total amount of energy which can be used up or released during a chemical reaction to equilibrium. In thermodynamic terms it has the formula:

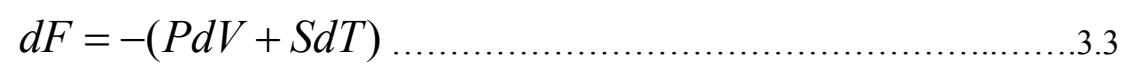

Where $\mathbf{P}$ is pressure, $\mathbf{V}$ is volume, $\mathbf{T}$ is temperature and $\mathbf{S}$ is entropy. A change in free energy $\mathbf{F}$ is also equivalent to the change in Exergy $\mathbf{E}$ of the system when proceeding to equilibrium. The formula has application to a thermodynamic system, in the manner of figure 6 referred to earlier, and through the cycle flow process, in the manner of figure 7.

In economic terms the free energy might better be described as Free Value $\mathbf{F}$, being the amount of useful value used up during a reaction between inputs such as materials, labour, capital stock and energy, potentially to produce output product. Equation (3.3) therefore represents an economic equivalent, relating Free Value $\mathbf{F}$ to price/cost $\mathbf{P}$, volume $\mathbf{V}$, entropy $\mathbf{S}$ and change in the index of trading value $\mathbf{T}$.

Some of the Free Value can be recovered at later points in the economic cycle, such as in recycling processes, the sale of an asset to another system, or consumption of some output by consumers and producers to regenerate capital and labour. There is however a net loss of Free Value (Exergy), which cannot be recovered. A significant part of economic production results in an irrevocable loss of Free Value from resources.

The above of course has some similarities to the processes of nature; though the difference is that the human economic system has not become sufficiently sophisticated and self-restraining to build into itself the feedback and time processes of nature. Thus oil (which took perhaps millions of years to be created), forests and fish stocks can get depleted.

In addition, the assumption is made that at the actual point of conversion of inputs into outputs, no change in the trading index $\boldsymbol{T}$ of either inputs or outputs occurs. Inputs are either just so before conversion, or instantaneously no longer there immediately after conversion; and likewise vice-versa for outputs. This can be more clearly seen if we combine equations (2.2) and (2.5) of this paper concerning a general stock and recognising that the nominal value $\mathbf{k}$ is unchanging:

Differentiating we have:

$$
P V=P(v N)=N k T
$$

$$
\frac{d P}{P}+\frac{d v}{v}+\frac{d N}{N}=\frac{d N}{N}+\frac{d T}{T}
$$

Thence if the assumption that $\mathbf{T}$ is unchanging is made, then any changes in price $\mathbf{P}$ are balanced out by changes in the throughput rate $\mathbf{v}$. These factors thus become irrelevant if a part of the input stock $\mathbf{N}$ is destroyed in the production process, to be replaced by an additional output stock in the product area.

Thus for either inputs or outputs at the system boundary, equation (3.3) can be reduced to:

$$
d F=-P d V
$$

Hence for a spontaneous reaction to take place to produce output, consumption (reduction) of free value $\mathbf{F}$ occurs, that is $\mathbf{\Delta F}$ is negative.

By substituting in $\mathbf{P V}=\mathbf{N k T}$ we have: 


$$
d F=-N k T\left(\frac{d V}{V}\right)
$$

Hence, by integration the free value change $\Delta \mathbf{F}$ between a starting point and an equilibrium point of either an input or output factor is:

$$
F=F_{o}-N k T \ln (V)
$$

Where the suffix o denotes a standard state position. At this stage, the input and out factors have been stated in terms of their stock equivalents and not monetary ones.

Although the factors of inputs and output are initially in arbitrary states, according to equations (3.1) and (3.2) however they have to combine/react in fixed proportions. Thus we write:

$$
\alpha[F]_{K}+\beta[F]_{L}+\delta[F]_{R} \Leftrightarrow[F]_{G}+\rho[F]_{D}
$$

And substituting in from equation (3.7) we have:

Free value of outputs $=\left[F_{o}-N k T \ln (V)\right]_{G}+\rho\left[F_{o}-N k T \ln (V)\right]_{D}$

Free value of inputs $=\alpha\left[F_{o}-N k T \ln (V)\right]_{K}+\beta\left[F_{o}-N k T \ln (V)\right]_{L}+\delta\left[F_{o}-N k T \ln (V)\right]_{R}$

Thence the change in free value $\mathbf{\Delta F}$ accompanying the reaction is the difference between these two:

$$
\Delta F=\left[F_{o}-N k T \ln (V)\right]_{G}+e t c-\alpha\left[F_{o}-N k T \ln (V)\right]_{K}-e t c
$$

At this stage the values of $\mathbf{N}, \mathbf{k}$ and $\mathbf{T}$ of the inputs and outputs all have very different forms. We are comparing apples with pears, humans with capital stock and resources, each with very different lifetimes and lifetime values. However, we do know that in a production process they combine together to produce output, and that a complementary reverse flow of money occurs when they do this. Thus we could replace the function (NkT) for each of the input and output factors $\mathbf{K}, \mathbf{L}, \mathbf{R}, \mathbf{G}$ and D by their monetary equivalents, as set out in section 2 of this paper, and, to a first approximation, remove this right outside of the square brackets, and assume a global monetary function for this.

Further, we could replace volume $\mathbf{V}$ for each input and output by the function (vN), as per equation (2.2). Thus we could to a first approximation replace equation (3.8) with:

$$
\Delta F=-(N k T)_{\text {money }}\left\{[\ln (v N)]_{G}+e t c-[\alpha \ln (v N)]_{K}-e t c+\left[F_{o}\right]_{G}+e t c-\left[\alpha F_{o}\right]_{K}-e t c\right\}
$$

Re-arranging equation (3.9) we have:

$$
\Delta F=\Delta F_{o}-(N k T)_{\text {money }} \ln \left[\frac{(v N)_{G}(v N)_{D}^{\rho}}{(v N)_{K}^{\alpha}(v N)_{L}^{\beta}(v N)_{R}^{\delta}}\right]
$$

Where $\Delta \mathbf{F}_{\mathbf{0}}$ is the change in free value accompanying the reaction, when all the reactants and products are in their standard states.

Now when the reaction has stopped, the change in free value $\Delta \mathbf{F}$ becomes zero, consequently from equation (3.10):

$$
\Delta F_{o}=(N k T)_{\text {money }} \ln \left[\frac{(v N)_{G}(v N)_{D}^{\rho}}{(v N)_{K}^{\alpha}(v N)_{L}^{\beta}(v N)_{R}^{\delta}}\right]_{o}
$$


Where the subscript $\mathbf{o}$ denotes the mix for the system at equilibrium. Since the standard free value change $\Delta \mathbf{F}_{\mathbf{0}}$ is the defined state of unit activity of the mix, it is apparent that $\Delta \mathbf{F}_{\mathbf{0}}$ must be constant, and it follows that the part of equation contained in the brackets must be constant too. Thence:

$$
\left[\frac{(v N)_{G}(v N)_{D}^{\rho}}{(v N)_{K}^{\alpha}(v N)_{L}^{\beta}(v N)_{R}^{\delta}}\right]_{o}=\psi
$$

Where $\boldsymbol{\Psi}$ may be called the Equilibrium Constant.

Finally by substituting equation (3.11) back into equation (3.10) we have an equation for the Free Value change (equals Exergy change) to equilibrium for the process:

$$
\Delta F=-(N k T)_{\text {money }} \ln \left[\left(\frac{N_{G o}}{N_{G}}\right)\left(\frac{N_{D o}}{N_{D}}\right)^{\rho}\left(\frac{N_{K}}{N_{K o}}\right)^{\alpha}\left(\frac{N_{L}}{N_{L o}}\right)^{\beta}\left(\frac{N_{B}}{N_{B o}}\right)^{\delta}\right] \ldots
$$

By turning round equation (3.13) we have:

$$
\left(\frac{N_{G o}}{N_{G}}\right)=\left[e^{\frac{-\Delta F}{(N k T)_{\text {mone }}}}\right]\left[\left(\frac{N_{K o}}{N_{K}}\right)^{\alpha}\left(\frac{N_{L o}}{N_{L}}\right)^{\beta}\left(\frac{N_{B o}}{N_{B}}\right)^{\delta}\left(\frac{N_{D}}{N_{D o}}\right)^{\rho}\right]
$$

Thus we can set out an equation for the change of the product stock $\mathbf{G}$ per unit of time when progressing from $\mathbf{N}_{\mathbf{G}}$ to $\mathbf{N}_{\mathbf{G O}}$ ) as:

$$
\frac{d[G]}{d t}=\left[e^{\frac{-\Delta F}{(N k T)_{\text {money }}}}\right]\left[(N)_{K}^{\alpha}(N)_{L}^{\beta}(N)_{R}^{\delta}(N)_{D}^{-\rho}\right] \ldots
$$

It can be seen that the equation structure is made up of a reaction rate factor [in the large square brackets] coupled with stocks of production factors with elastic indices $\alpha, \beta$ etc, and a waste function with a negative elastic index. The reaction factor has the same format as that defined in the Arrhenius Equation (Swedish scientist Svante Arrhenius 1859-1927), which is a mathematical expression used in chemical kinetics to link the rate of reaction to the concentration of the reactants.

From equation (3.15) it can be seen that the key determinants of the rate of reaction are:

- The level of negative free value change $\mathbf{\Delta} \mathbf{F}$ or disequilibrium necessary for the economic process to take place. Economies that are able to operate with a low difference are likely to have higher rates of output. The equivalent in a chemical system is called the energy of activation. The higher this is the less likely that a spontaneous reaction will occur. The easiest way to imagine the economic process is in terms of the cash reserves necessary fund a production run, and items such as start-up technology costs or ordering costs.

- The index of trading value (velocity of circulation) T. The higher this, the higher the level of output per unit of time. Thus, for example, an economy with a higher level of planned obsolescence and with no constraint on waste or resources, enabling it to discard and replace assets quickly with shorter lifetimes will have a higher level of output volume per unit of time.

- The relative level of resource availability, compared to capital and labour. The higher the availability of resources, the more capital and labour can be utilised to produce output, with a consequent feedback to create more capital and labour stocks.

- Likewise, the lower the level of accumulated waste (or the greater efficiency with which it is removed and returned and absorbed into the environmental and ecological cycles) the higher the potential output level.

- The level of consumer stocks - the lower these are the higher the potential output level. Thus high obsolescence, with low lifecycle and low saturation promote the forward path.

- The relative dependence of an economy on using resources (in particular, energy) to replace labour and augment other resource usage (such as food production).

- The relative level of capital stock available to augment and improve the efficiency of energy and resource level usage. 
The dynamic nature of equation (3.15) becomes apparent when we consider a series of processes joined together, as per figure 7, with processes to renew the position at each cycle. At figure 8 it can be seen that the rate of flow is dependent upon the position in the non-flow process, as per the slope of the dotted line a-a. But if the process is averaged over many cycles, and if inputs and outputs are flowing steadily in an out, then we might approach an average flow, as per the slope of lines bb.

Figure 8 Production Process

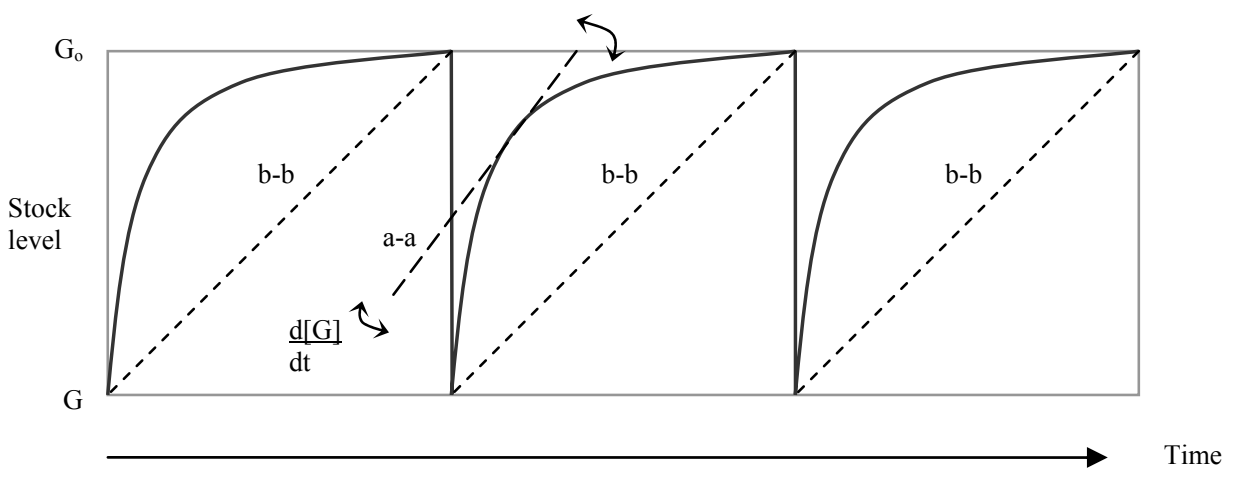

Thus capital stock depreciates and is replaced by new investment; labour retires and is replaced by recruitment of new personnel, and resource stocks are replenished by reordering. If one factor is used up - for example, product $\mathbf{G}$ is sold on to the next system - then the system produces more $\mathbf{G}$. Likewise as a resource $\mathbf{R}$ is used up, it is replaced from another system, which perceives demand for its product, and so the reaction goes on. We have derived an inter-reacting trading process, with free value continually being used up by one system and replaced by another.

At first sight equation it would appear that equation (3.15) has similarities in construction to the well-known Cobb-Douglas production function with a Hicks-neutral technical progress function added [Hicks, J. (1932)] - viz:

$$
V_{G}=\left[A_{0} e^{\lambda t}\right](N)_{K}^{\alpha}(N)_{L}^{\beta}
$$

However, there are some key differences.

First resources and waste are often excluded from the Cobb-Douglas equation, whereas in the thermodynamic equation these are considered key components in assessing long term sustainability. Work by Ayres and Warr [Ayres, Warr (2003)] has shown that exergy consumption in an economy likely explains more of economic growth than do changes in components of capital stock and labour.

Second, the Hicks technical progress function assumes exponential growth forever into the future. The thermodynamic approach does not make this assumption. Long-run growth will only occur if resources can be continually developed to accommodate it, and waste stocks are minimised and re-absorbed into the environment.

The nature of the above exposition indicates that output is a complex, dynamic function of stocks and flows, with elements of systems dynamics, with an equilibrium position that is continually varying, moving to the left or to the right, depending upon the stock quantities of each factor.

It is not the intention of this particular paper to develop a full systems analysis, as that must be the subject of further investigation, and would make the paper far too long. The analysis set out so far in this paper does, however, give rise to a number of basic kinetic models and principles relevant to a thermodynamic theory of economics, which will now be briefly described. 
First, if we suppose that the number of stocks is reduced to a single economic component $\mathbf{A}$, with only an output and no replacing input, such as a perfectly defined stock of known absolute size $\mathbf{C}_{\mathbf{A}}$ that cannot be replaced or augmented by successful prospecting, then from equation (3.15) the rate of reaction becomes directly proportional to the concentration of the single reacting economic component. Thus:

$$
\frac{d C_{A}}{d t}=-\varphi C_{A} \ldots \ldots \ldots \ldots \ldots \ldots \ldots \ldots \ldots \ldots \ldots \ldots \ldots .1
$$

The mathematics of this reaction is simple, being a declining exponential function, with the formula representing a declining balance stock with a depreciation or depletion rate of $\boldsymbol{\varphi}$.

$$
C_{A}=a e^{-\varphi t}
$$

Where ' $\mathbf{a}$ ' is the original concentration of $\mathbf{A}$. The stock has a half-life, rather like a radio-active substance.

Figure 9 Single Economic Component

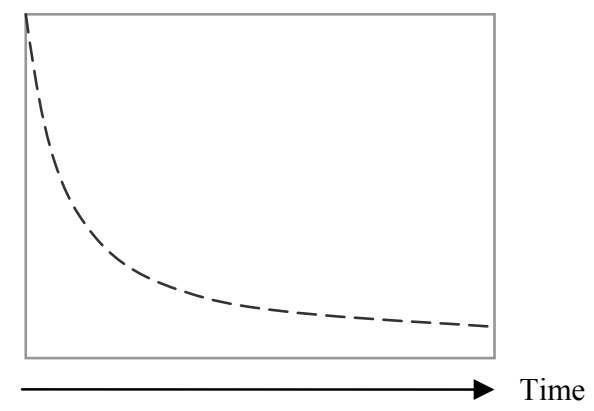

Capital and labour stocks are of course more complex than this, having both inputs and outputs, of investment/depreciation, recruitment/retirement and births/deaths via the population cycle. It is nevertheless possible to imagine a two-way process, with a forward reaction having a depreciation rate of $\varphi$ per unit of time, and a reverse reaction having a creation rate of $\varphi^{\prime}$.

$$
C_{A}=a e^{-\left(\varphi-\varphi^{\prime}\right) t}
$$

Although there are large time lags between inputs and outputs, if the rate of investment $\varphi^{\prime}$ is greater that the rate of depreciation $\varphi$, then there will be a net growth in the stock, with a growth rate of $\left(\varphi^{\prime}-\varphi\right)$. For a reversible reaction of this kind, the equilibrium constant $\psi$ from equation (3.12) becomes equal to:

$$
\psi=\frac{\varphi}{\varphi^{\prime}}
$$

The birth rate or rate of investment is of course dependent upon human decision, having regard to current conditions and expectations of the future.

For a more extended process reaction where a resource $\mathbf{A}$ is converted to a product $\mathbf{B}$, which is subsequently converted to product $\mathbf{C}$, we could write:

$$
A \stackrel{\varphi_{1}}{\rightarrow} B \stackrel{\varphi_{2}}{\rightarrow} C
$$

If the initial concentration of resource $\mathbf{A}$ was ' $\mathbf{a}$ ', then after a period of time $t$ it can be readily seen that:

$$
a=C_{A}+C_{B}+C_{C}
$$

Solving this process involves two differential equations: 


$$
-\frac{d C_{A}}{d t}=\varphi_{1} C_{A} \text { and }-\frac{d C_{B}}{d t}=\varphi_{1} C_{A}-\varphi_{2} C_{B}
$$

Giving:

$$
C_{A}=a e^{-\varphi_{1} t} \text { and } C_{B}=a\left(\frac{\varphi_{1}}{\varphi_{2}-\varphi_{1}}\right)\left(e^{-\varphi_{1} t}-e^{-\varphi_{2} t}\right) \ldots \ldots \ldots \ldots \ldots \ldots \ldots \ldots .6
$$

A last process to consider, before leaving this section, is that of the development of a resource. When considering a resource with a ready infrastructure to utilise and convert it into product, the likely picture of development is that shown in figure 9. The reality of the situation, however, for a resource such as oil or gas, is that the infrastructure required, such as oil-well equipment, power stations, cars, roads, oil tankers, pipelines and all the capital stock needed to use the resource reserves, has to be developed over time. In the early stages therefore output tends at first to grow slowly, being dependent upon the infrastructure in place, before later proceeding at a faster rate. In addition, ultimate knowledge of the extent or usefulness of resource reserves is not always known in the development phase of the cycle. This suggests a more complex development involving S-shaped curves of accumulated production and accumulated consumption; as illustrated in the upper diagram at figure 10, with product accumulation shown by the solid line and resource usage shown by the dotted line. The usage level accelerates as the curves proceed and then declines as the process draws to its close.

Figure 10 Logistic Curves
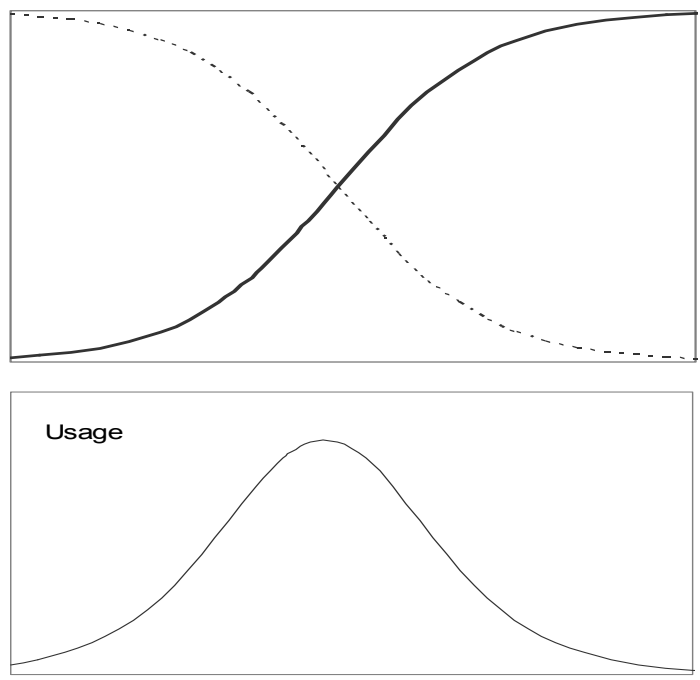

Such curves belong to the Logistic family of models, of which the Verhulst equation [Pierre Verhulst 1804-1849] and the Gompertz and Sigmoid functions are the more well known. These models find use for example in estimating saturation levels of population and consumer durables. The growth of civilisations tends to follow an S-shaped curve, but some civilisations can also decline, such as the Roman empire. The Verhulst equation has the following differential form:

$$
\frac{d C_{A}}{d t}=\varphi C_{A}\left(1-\frac{C_{A}}{R}\right)
$$

Where $\mathbf{C}_{\mathbf{A}}$ is the size of the stock $\mathbf{A}$, and $\mathbf{R}$ is the ultimate size of the stock or resource reserve. The solution to this equation is shown at equation (4.8), where $\mathbf{C}_{\mathbf{A} \mathbf{0}}$ is the initial starting level:

$$
C_{A}(t)=\frac{R C_{A 0}}{\left(R-C_{A 0}\right) e^{-\varphi t}+C_{A 0}} \ldots \ldots \ldots \ldots \ldots \ldots \ldots \ldots \ldots \ldots \ldots \ldots \ldots \ldots \ldots \ldots \ldots . .8
$$

Fitting the above equation to real data is not a simple exercise. Specifically, some knowledge is required of the likely ultimate level of $\mathbf{R}$, along with evidence of when the turning point at the middle of the curve at figure 10 will occur.

All of the above functions are related to differential equations commonly used in systems dynamics. We now turn to discussion and analysis of trends in world energy resources and of climate change to illustrate some of the principles. 


\section{Energy Consumption}

Economic systems, particularly those of developed countries, have become progressively embedded in an energy base, to provide a source of productive power and human wealth and well-being. Energy consumption provides electricity, powers machines in industry and computers, provides heat for industry and homes, and powers road, rail and sea transport. Fishing and agriculture (including the manufacture of fertilisers) in developed economies are now significantly dependent on energy, rather than man or animal power.

Energy is now an international commodity, and few countries with a significant manufacturing and commercial base can now be described as 'closed' with respect to energy. USA oil production peaked in about 1970 and the USA now imports $2 / 3^{\text {rd }}$ of its oil requirements [BP Statistical Review 2008]. Of the major economies, only Mexico, Canada and Norway can claim to be net exporters of oil. In the natural gas market, the USA and Europe are now net importers of gas via pipelines respectively from Canada and Russia. Only in the coal industry is consumption met mostly by local production, with China and USA accounting for $60 \%$ of world production and consumption.

Figures 11, 12 and 13 summarise the development and relationship of primary energy consumption and electricity consumption as inputs to GDP over several decades. By common practice, the units used to measure energy output are those of weight (tonnes of oil), volume (cubic metres of gas) or the heat value of sources of energy (Joules, BTU's). These can be equated to 'productive content' or exergy if account is taken of the net energy delivered to the environmental average. The example of a gusher oil well compared to tar sands was used earlier in this paper to describe the net energy delivered to the system. Industry and nations take account also of the money flow in the opposite direction, in terms of wage costs, profits, transport and import costs in measuring contribution to GDP.

Figure 11 Primary Energy Consumption per Capita (toe) versus GDP per Capita 1965 - 2004 (World 1980 onwards, Russia 1990 onwards)

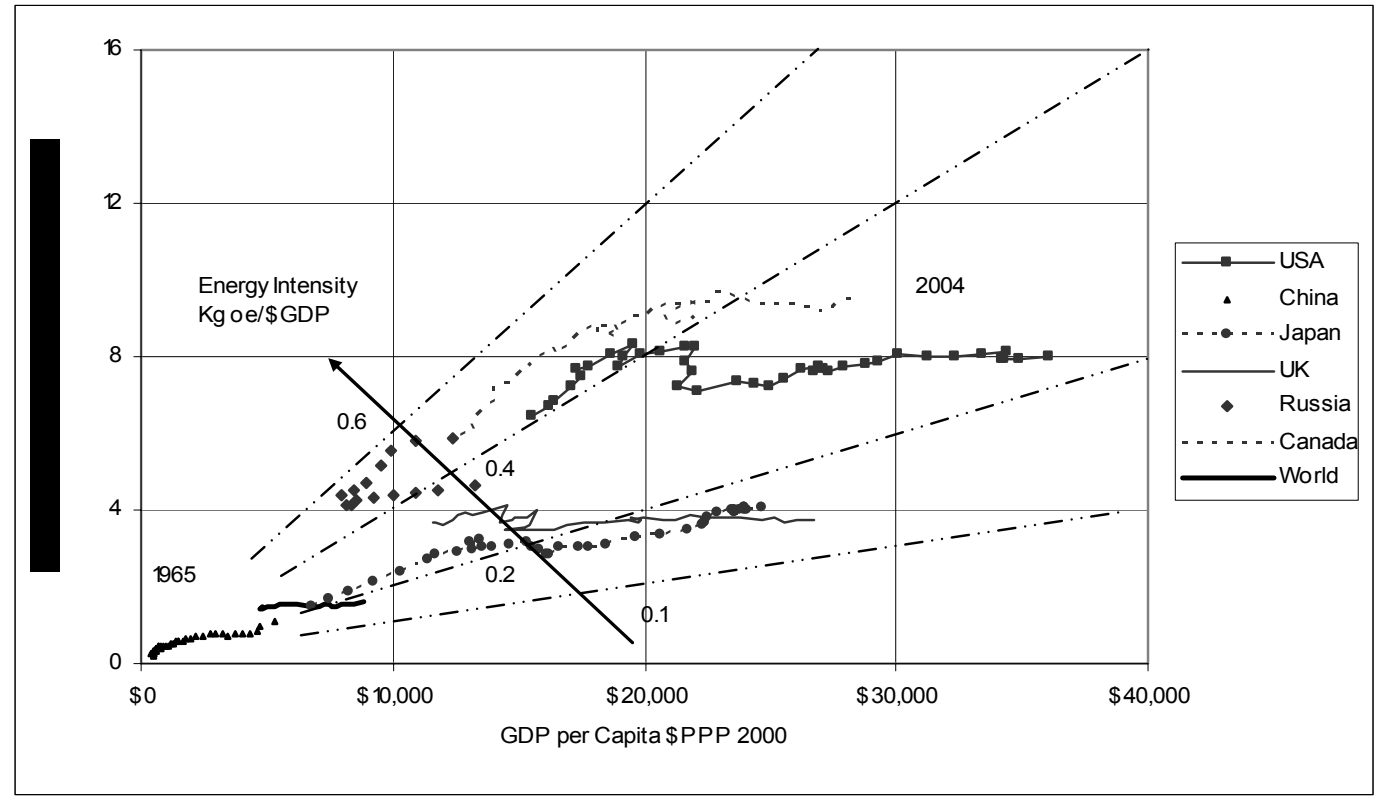

Penn World, BP

In some developed economies, energy consumption per capita has begun to level off, but in the developing world, illustrated by China, energy consumption per capita continues to grow. Energy intensity (energy/GDP) has fallen significantly for all countries, but has funnelled down to a narrower range than four decades previously. However, bearing in mind that electricity production accounts for some $40 \%$ of primary energy consumption, it should be noted that per capita electricity consumption is still rising, associated with only a small decline in electricity intensity (ratio electricity consumption/GDP). Thus a significant part of the reduction in energy intensity has been owing to improved efficiency in conversion of energy into electricity, though ultimately the laws of thermodynamics place limits on the level of efficiency that can be obtained from converting energy sources into power. 
The International Energy Agency indicate [IEA Worldwide Trends in Energy Use \& Efficiency (2008[1])] that potential for further savings in primary energy consumption could be between $18 \%-26 \%$ in industry, and $23 \%-32 \%$ in electricity generation.

Figure 12 Electricity Consumption per Capita versus GDP per Capita 1980 - 2004

(World 1980 onwards Russia 1990 onwards)

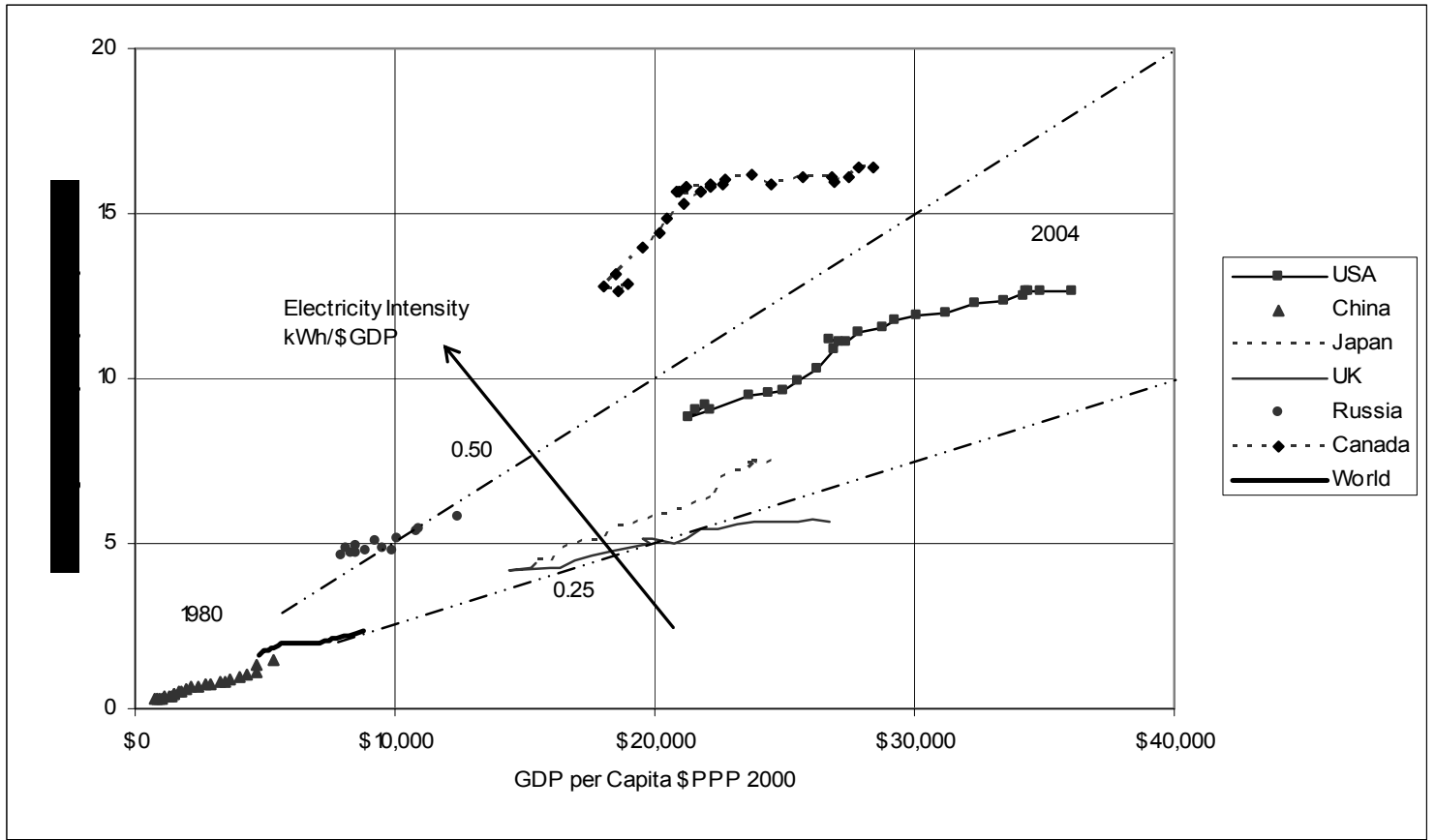

Penn World, EIA

Figure 13 Energy Intensity for Selected Countries 1965-2004 (World 1980 onwards, Russia 1990 onwards)

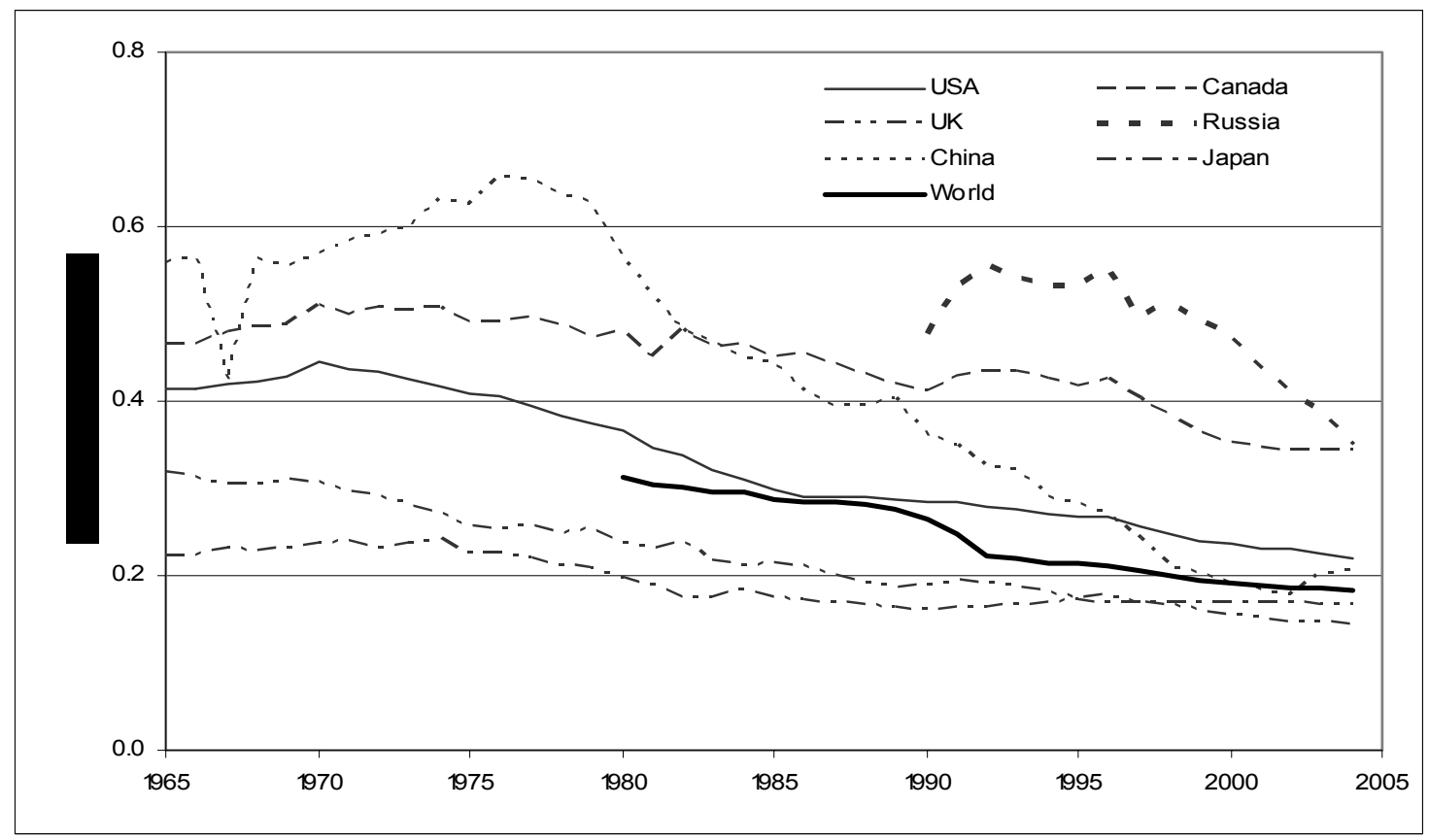

Penn World EIA

The position therefore is that for several decades energy consumption has been a key input to the level of GDP, as per equations (2.17) and (3.15), and any major change in the supply of energy will have a significant effect thereon. 


\section{Energy Capital Stock}

The use of energy in an economy is through the installation of associated capital stock. In the UK, for example, while dwellings constituted $40.6 \%$ of total net capital stock in 2007 , the residual $59.4 \%$ was split:

- Electricity, gas \& water $\quad 5.6 \%$

- Transport equipment $\quad 4.7 \%$

- Other transport assets $\quad 7.6 \%$

- Distribution $11.1 \%$

- Other plant \& machinery $\quad 16.2 \%$

- Residual non-dwelling buildings \& structures $\quad 54.8 \%$

[Source: Blue Book]

Figure 14 sets out changes in the relationships between GDP, capital stock and population, and between GDP, energy consumption and capital stock, for three leading economies:

Figure 14 GDP, population, capital stock and primary energy consumption (tonnes oil equivalent)
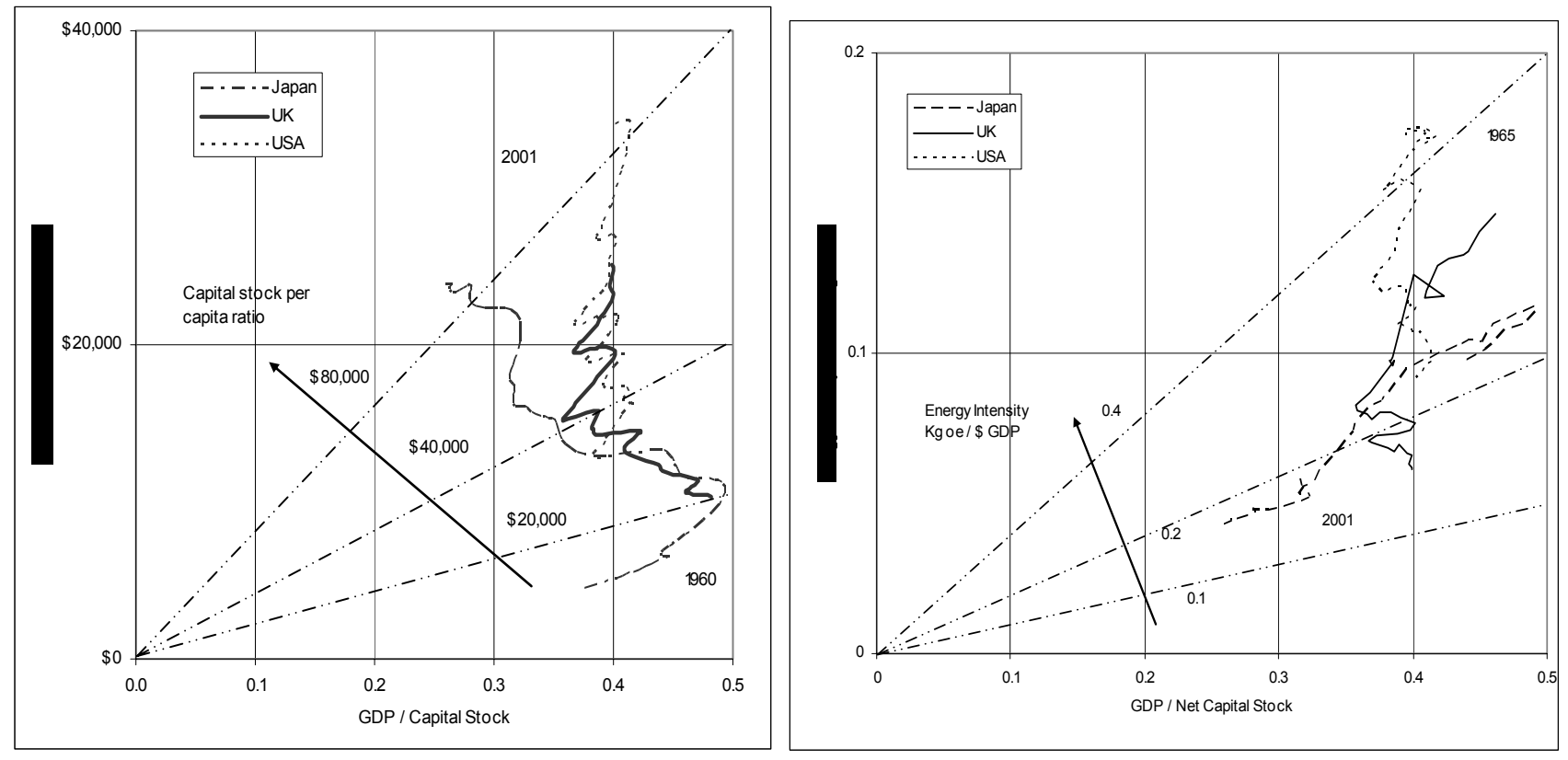

Source Kamps, OECD, BP, Penn World

It can be seen that GDP per capita has risen against a static or declining level of GDP/capital stock. Alongside of this has been a significant decline in energy consumption in relation to the capital stock, which indicates either that capital stock is becoming less energy intensive, or that the capital stock processes less energy, either way resulting in a decline in energy intensity to GDP, which was displayed at figures 11 and 13.

\section{Energy Reserves}

According to the US Energy Information Administration, oil, natural gas and coal accounted for 37\%, 23\% and $27 \%$ respectively of total world primary energy consumption in 2005 , with the remaining $13 \%$ coming from nuclear, hydro, wind and other sources. Given the long timescales associated with nuclear technology, it is likely that consumption of oil, natural gas and coal will remain important to future levels of GDP, and an analysis of their reserves position, impacting on the right hand sides of equations (2.17) and (3.15) is pertinent. 
Figure 15 is a diagrammatic representation of a non-renewable energy resource such as oil, gas and coal, similar in construction to the Logistic curves set out at figure 10 and described by equations (4.7) and (4.8). At a current point in time, information is known of production and cumulative production to date. Knowledge of remaining net proved reserves that are being tapped will also be known from geological data. Information to the public on proven reserves is provided by oil companies and individual governments, and recorded by bodies such as Oil \& Gas Journal, BP and EIA.

Figure 15 A Non-renewable Energy Reserve
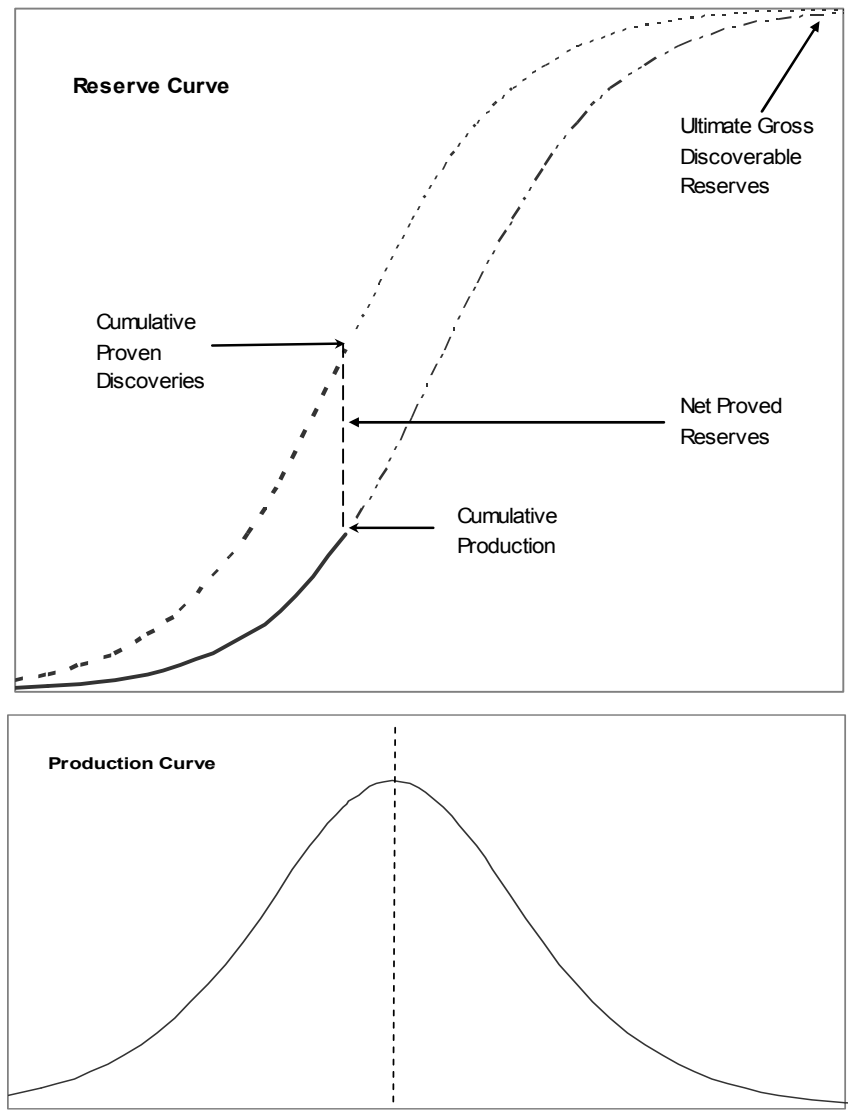

What is not known for certain is what other reserves may be discovered in the future. Oil and gas professionals do have at their disposal some techniques to estimate future discoveries. One such technique is creaming, which is based on the knowledge that the easiest energy fields are those that are discovered first and the more difficult ones later [International Energy Agency (2004)]. Others experts extrapolate from current production using the Hubbert equation [M King Hubbert (1956)], which is based on the Logistic/Verhulst equation set out earlier in this paper.

In respect of oil, there is a significant element of politics surrounding some countries' estimates of what are declared as proven reserves. Laherrere [Laherrere, J. (2005, 2006 ASPO)], points to 'backdated mean technical reserves' as a measure independent of oil companies and national agencies' official figures. He concludes that since 1980 oil discoveries have been less than production. Groups such as the Energy Watch Group and the Association for the Study of Peak Oil \& Gas also have doubts on the official position.

If cumulative production proceeds against a finite reserve, there will come a turning point when production peaks. This is at about the middle of the graph at figure 15 - the so-called 'peak oil' phenomenon. Thereafter production begins to wind down as the remaining reserves reduce. Such a peak was reached in the USA oil industry in about 1970. The only way in which production can increase in perpetuity is by the discovery of new energy resource fields - of ever increasing size and numbers. However, knowledge of the ultimate level that proven reserves may reach is not known for certainty, and therefore estimating the peak size and when it may occur is an exercise in trend analysis, sensitive to determining the turning point. There is much debate on when world 'peak oil', 'peak gas' and 'peak coal' may occur, depending upon views held on the ultimate level of proven usable reserves, where the level of energy abstracted is greater than that put in to develop such reserves. 
Figures 16 and 17 set out graphs of world cumulative production, official net proven reserves and total proven reserves to date, for both oil and natural gas.

Figure 16 World Oil Reserves and Cumulative Production
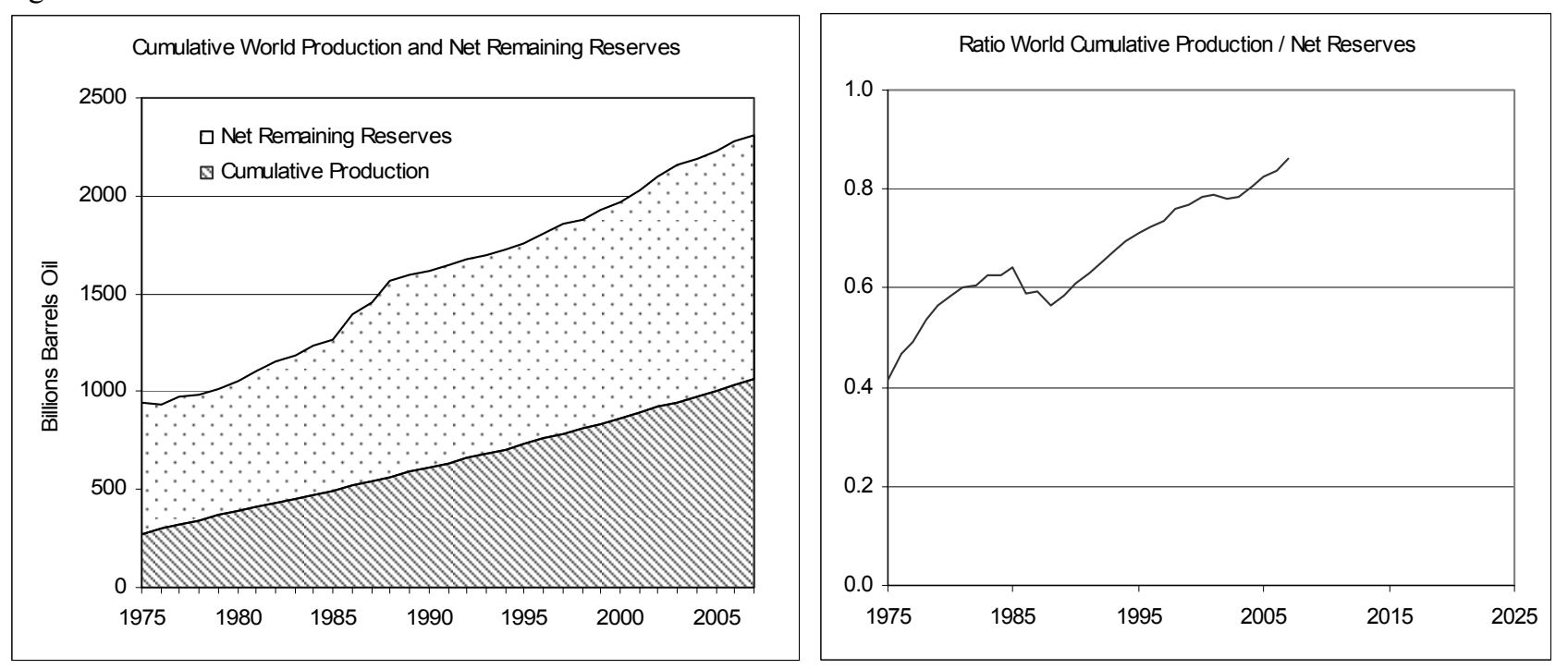

Sources: BP, EIA.

Cumulative world oil production as a proportion of official net proven reserves remaining (not including tar sands) continues to rise, and is approaching a 1:1 ratio, indicating perhaps that production is nearing the peak illustrated at figure 15. On present trends, based on oil companies' and national agencies' estimates of net reserves, peak oil may occur in about a decade. On more pessimistic estimates of the level of net reserves, the peak may arrive earlier or, indeed, may already have arrived. Estimates of ultimate recoverable reserves range from 3.5 trillion barrels of oil [IEA WEO (2008], down to 3 trillion [Laherrere (2006)], 2 trillion excluding extra-heavy oil. The position with natural gas appears to be further behind oil, though it is a matter of evidence as to whether gas reserves yet to be discovered will occur.

Figure 17 World Natural Gas Reserves and Cumulative Production
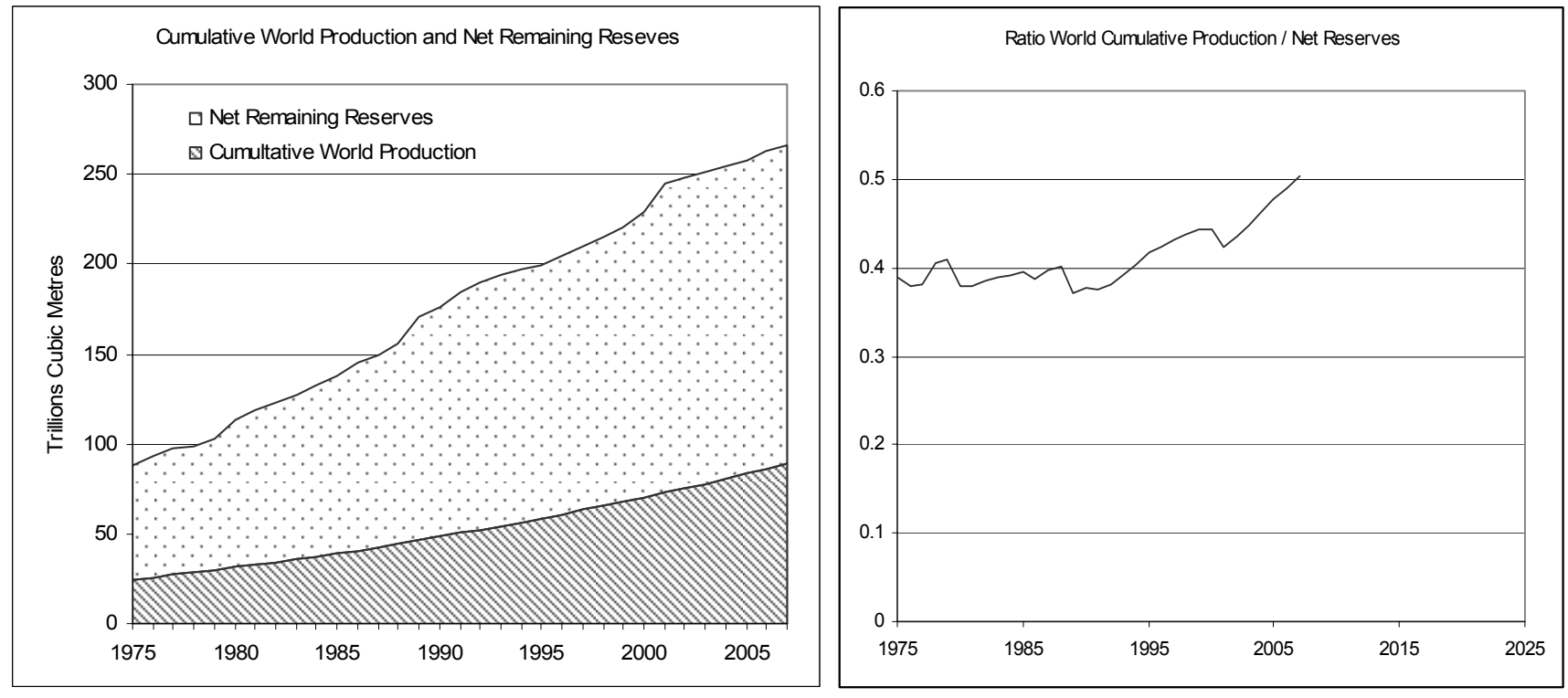

Sources: BP, Laherrere ASPO

Figure 18 summarises world oil and natural gas production per annum. The shape of the graphs corresponds to a part of the left-hand side of the production curve at figure 15. It is a matter of debate as to when production, and thereby consumption of oil and gas, will peak and begin to decline. 
Figure 18 World Oil and Natural Gas Production
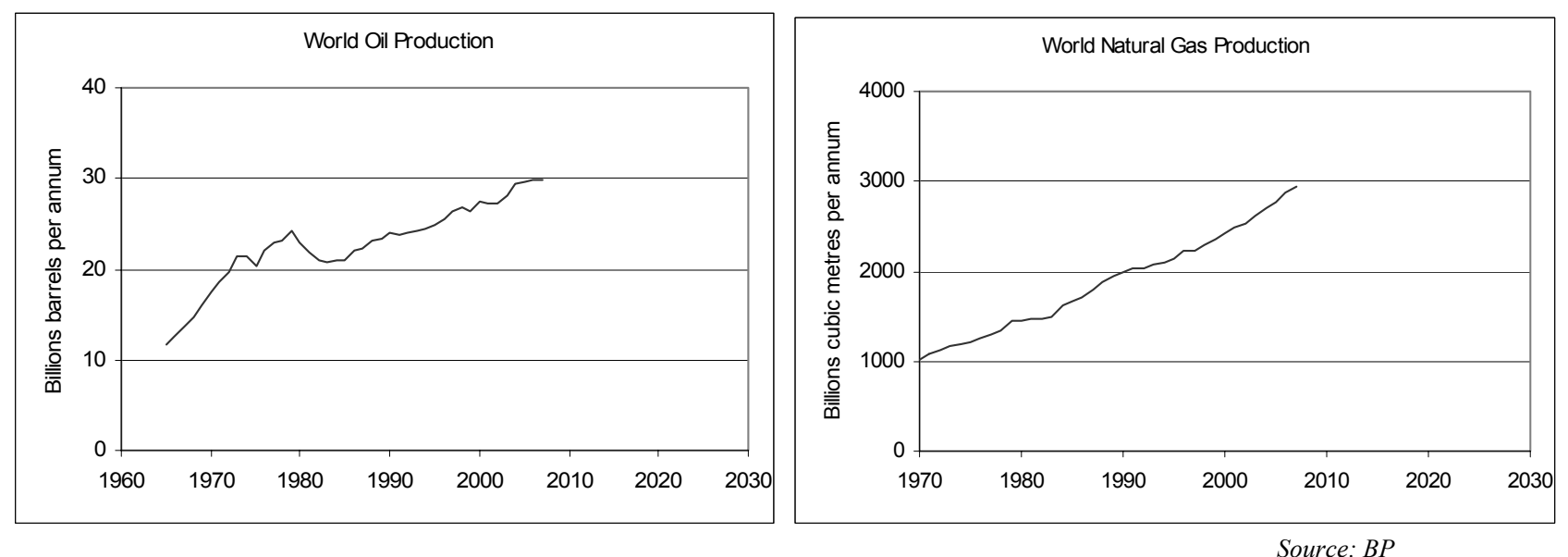

Of course, if new proven reserves of oil and/or natural gas are found, of sufficient economically extractable volume to increase significantly the ratio of net reserves to cumulative production, then peak production may be put off further, or production may flatten off at a higher level for a period. On the assumption, however, that a peak is reached, it might be expected that production might then decline in level, approximately in an inverse manner to the charts at figure 18.

Besides oil, and later, natural gas, there is also some debate as to the extent of world coal reserves. According to the World Energy Council [BP statistical review 2008], total world proved reserves stood at 847 billion tonnes of coal; split about half bituminous/anthracite and half lignite/sub-bituminous - the latter being of inferior quality to the former. This appears to represent a reserves-to-production $(\mathrm{R} / \mathrm{P})$ ratio of 133 years. Approximately $82 \%$ of these reserves are held by six countries: USA, Russia, China, Australia, India and South Africa. Coal is not widely-transported worldwide, being predominantly consumed in the country where it is produced. China and USA account for $60 \%$ of production and consumption. A report of the Energy Watch Group [EWG-Series No1/2007] concludes, however, that data on coal reserves is poor, the data for China for example being last estimated in 1992 , even though $20 \%$ of reserves in that year have since been consumed. The report points out that worldwide coal reserves have been downgraded significantly, and estimates that global production may continue to increase over the next 10-15 years, reach a plateau, and then gradually decline. Such a picture is not dissimilar to the curves for oil and gas, though perhaps set later.

All of the above does not presage a sudden slump in production and consumption but that, over time, the world economic system may eventually have to make do with less and less energy per annum from conventional sources. On this basis, and the theory set out in this paper, it might be expected that a levelling off of reserves would eventually feed its way into a reduction in energy production. Working backwards, this would feed into a reduction in the input to GDP, which would in turn lead to a levelling or decline in GDP, moving the equilibrium position at equation (3.1) to the left.

While there may still be some gains to be made from improving the efficiency of fuel use increasing net exergy delivered to economic output (subject to limits set by the Laws of Thermodynamics), and compared to the reductions in energy intensity achieved over the last 40 years (see figure 11), large improvements may only be achieved by finding substitutes for conventional energy resources, such as nuclear and wind generated electricity, with ground transport increasingly switching to electric energy, and entailing changes to the capital stock. It is however more difficult to imagine air and sea transport changing in a similar fashion. The alternatives are for a quantum shift in consumers' attitudes to energy use, removing a part from GDP and permanently altering the mix of equation (3.1); or, a long-term decline in GDP may lead to a reduction in GDP per capita, unless population also declined in proportion.

Thus the conclusions of the analysis so far is that energy availability will play a significant part in the development of economic output, but that just extrapolating exponential growth into the future in the manner of technical progress and capital and labour does not form a sound basis for economic planning. Of the equations of reaction kinetics set out at section 4, the Logistic form, equations (4.7) and (4.8), most closely fits the picture of economic development in oil, gas and coal reserves. 


\section{Population}

Associated with the benefits of economic growth and energy consumption has been an increase in world population. It is a matter of opinion as to whether population size may now be approaching a ceiling within a finite world. There are indications that feedback, perhaps along the lines of the two-way economic process illustrated by equation (3.1) has reduced birth rates in some areas of the world. Between 1980 and 2004, population growth in East and West Europe has been only 10\%. However, growth elsewhere has been larger - North America 34\%, Asia \& Oceania 44\%, Central \& South America 52\%, Africa 85\% and the Middle East $93 \%$. In China measures to control family size have been in place for some time. The Russian population is currently declining. The US Census Bureau projects a world population level of $9 \mathrm{bn}$ by $2042,36 \%$ more than the current level.

Figure 19 Population growth rates in selected countries and the world - percent per annum

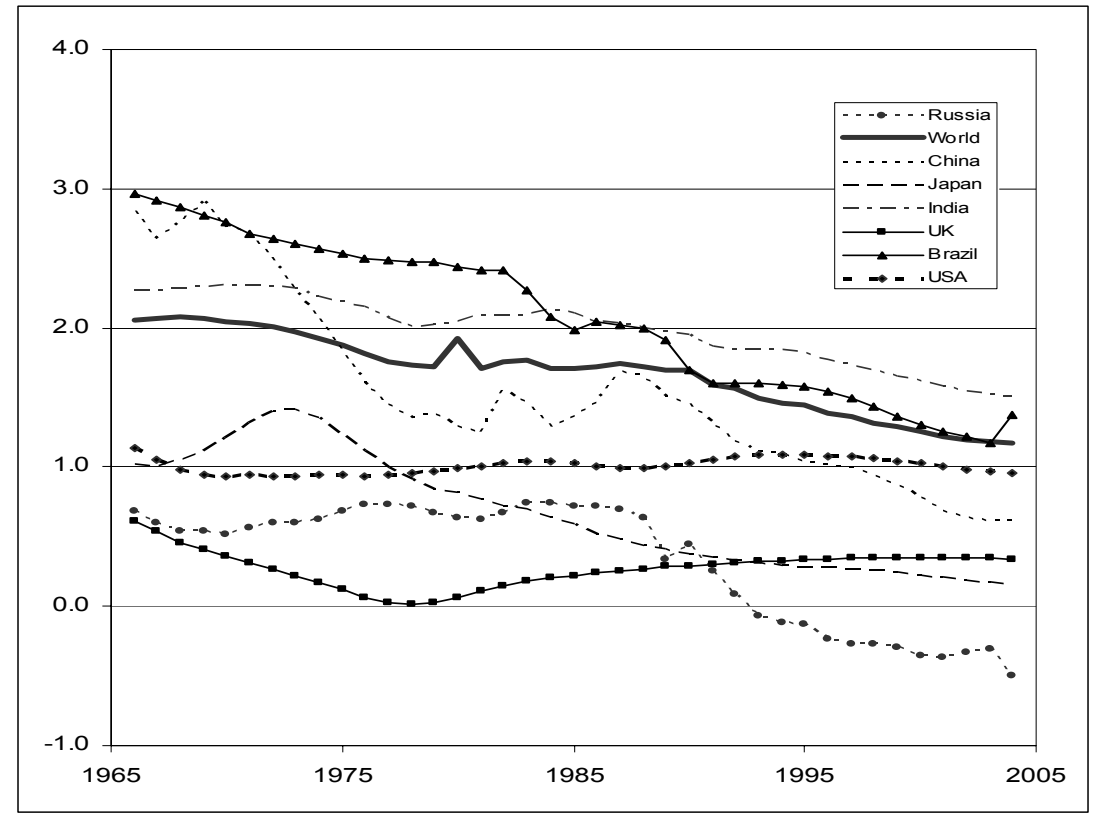

\section{Climate Change}

Studies carried out by the Intergovernmental Panel on Climate Change [IPCC] and other agencies all point to the necessity of reducing or containing the impact of greenhouse gases on the world environmental climate and atmospheric temperature, though there continues to be some debate on the probable outcome. The scenarios painted by the agencies do, however, illustrate a point of this paper, that restrictions placed on economic systems can potentially affect their forward path in quite a dramatic way, moving the equilibrium position at equation (3.1) to the left, and the impact of the analyses presented to a world audience may enact feedback to construct policies to change the shape of the future. In the case of climate change, the restriction arises on the right-hand side of equation (3.1) increasing the costs associated with a waste function.

There is of course nothing to prevent world economies continuing along their historic growth path, as they appear to have done so far, but without policies in place to reduce greenhouse gases, the probability is that temperatures and water levels will rise, to the potential detriment of the eco-system. Whereas, from the earlier resource analysis, any limits in oil, gas and coal reserves will ultimately automatically feed back into reduced energy consumption, no such automatic feedback is likely with regard to achieving the required reduction in emissions. Instead the required action to avert temperature rises is dependent upon agreement and co-operation among the international community.

Approximately $55 \%$ of world $\mathrm{CO}_{2}$ emissions increases arise from fossil fuel use, and the rest from deforestation, agriculture and other areas [IPCC SPM 1]. Table 1 and figure 20 illustrate the structure and trends in $\mathrm{CO}_{2}$ emissions, relating to consumption and flaring of fossil fuels, GDP and population. 
Table 1. $\mathrm{CO}_{2}$ Output, Primary Energy Consumption, GDP, and Population

\begin{tabular}{|c|c|c|c|c|c|c|c|c|c|}
\hline & $\begin{array}{r}\mathrm{CO}_{2} \text { Output } \\
\text { mn toe pa }\end{array}$ & $\begin{array}{r}\text { Carbon } \\
\text { Intensity } \\
\mathrm{CO}_{2} / \mathrm{PEC} \\
\text { ratio } \\
\end{array}$ & $\begin{array}{r}\text { Primary } \\
\text { Energy } \\
\text { Consumption } \\
\text { mn toe pa }\end{array}$ & $\begin{array}{r}\text { Energy Intensity } \\
\text { Energy/GDP } \\
\text { Kgoe/\$ }\end{array}$ & $\begin{array}{r}G D P P P P \text { * } \\
\text { bn } \$ p a\end{array}$ & $\begin{array}{r}\text { Population } \\
\text { mn } \\
\end{array}$ & $\begin{array}{r}\text { GDP/Hd } \\
\$ p a\end{array}$ & $\begin{array}{r}\text { PEC/Hd } \\
\text { toe pa }\end{array}$ & $\begin{array}{r}\text { Emission } \\
\text { Intensity } \\
\text { CO2/GDP } \\
\mathrm{Kg} / \$\end{array}$ \\
\hline USA & 5696.8 & 2.4548 & 2320.7 & 0.2060 & $\$ 11,265$ & 299.8 & $\$ 37,572$ & 7.740 & 0.5057 \\
\hline China & 5606.5 & 2.9840 & 1878.8 & 0.2163 & $\$ 8,685$ & 1311.8 & $\$ 6,621$ & 1.432 & 0.6455 \\
\hline Russia & 1587.2 & 2.3472 & 676.2 & 0.4589 & $\$ 1,474$ & 142.5 & $\$ 10,340$ & 4.745 & 1.0771 \\
\hline India & 1249.7 & 2.2087 & 565.8 & 0.1541 & $\$ 3,671$ & 1109.8 & $\$ 3,308$ & 0.510 & 0.3404 \\
\hline Japan & 1212.7 & 2.2987 & 527.6 & 0.1491 & $\$ 3,538$ & 127.8 & $\$ 27,694$ & 4.129 & 0.3428 \\
\hline Germany & 823.5 & 2.3625 & 348.6 & 0.1546 & $\$ 2,255$ & 82.4 & $\$ 27,373$ & 4.232 & 0.3652 \\
\hline Canada & 538.8 & 1.9976 & 269.7 & 0.2652 & $\$ 1,017$ & 32.6 & $\$ 31,178$ & 8.269 & 0.5298 \\
\hline UK & 536.5 & 2.3211 & 231.1 & 0.1322 & $\$ 1,749$ & 60.5 & $\$ 28,888$ & 3.818 & 0.3068 \\
\hline South Korea & 476.1 & 2.1991 & 216.5 & 0.2135 & $\$ 1,014$ & 48.3 & $\$ 20,992$ & 4.482 & 0.4696 \\
\hline Italy & 448.0 & 2.4327 & 184.2 & 0.1200 & $\$ 1,535$ & 58.9 & $\$ 26,078$ & 3.129 & 0.2919 \\
\hline Australia & 394.5 & 3.2208 & 122.5 & 0.1938 & $\$ 632$ & 20.7 & $\$ 30,469$ & 5.905 & 0.6242 \\
\hline Mexico & 416.3 & 2.3461 & 177.4 & 0.1722 & $\$ 1,030$ & 104.8 & $\$ 9,838$ & 1.694 & 0.4039 \\
\hline Spain & 327.7 & 2.2665 & 144.6 & 0.1382 & $\$ 1,046$ & 44.1 & $\$ 23,731$ & 3.280 & 0.3133 \\
\hline Brazil & 332.4 & 1.4832 & 224.1 & 0.1518 & $\$ 1,477$ & 189.3 & $\$ 7,800$ & 1.184 & 0.2251 \\
\hline Rest of World & 7978.9 & 2.2290 & 3579.5 & 0.2312 & $\$ 15,482$ & 2839.5 & $\$ 5,452$ & 1.261 & 0.5154 \\
\hline World 2006 & 28003.0 & 2.3853 & 11740.0 & 0.2039 & $\$ 57,564$ & 6536.0 & $\$ 8,807$ & 1.796 & 0.4865 \\
\hline World 2000 & 23850.0 & 2.5618 & 9310.0 & 0.1916 & $\$ 48,600$ & 6080.0 & $\$ 7,993$ & 1.531 & 0.4907 \\
\hline
\end{tabular}

Source: IEA

Figure 20 Carbon Intensity - ratio $\mathrm{CO}_{2}$ emissions from consumption \& flaring of fossil fuels / primary energy consumption (tonnes $\mathrm{CO}_{2}$ / tonnes oil equivalent) 1980 - 2004

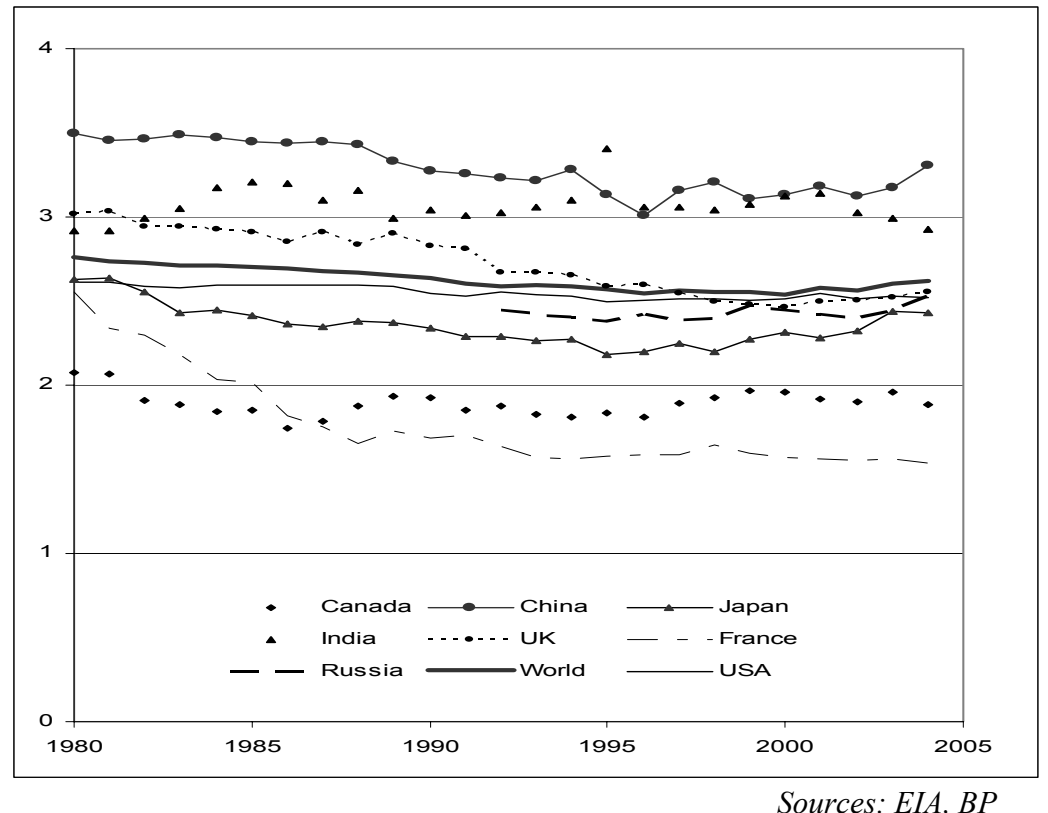

In 2006, the top five countries, USA, China, Russia (all high consumers of coal) plus India and Japan accounted for nearly $55 \%$ of global $\mathrm{CO}_{2}$ output from consumption and flaring of fossil fuels. World emission intensity $\left(\mathrm{CO}_{2} / \mathrm{GDP}\right)$ at 2006 stood at $0.486 \mathrm{Kg} / \$$ of output, a $1 \%$ reduction on the figure for 2000 , and a $44 \%$ reduction on the figure for 1980 . World GDP, of course, has been marching onwards, with a resultant significant increase in $\mathrm{CO}_{2}$ production from fossil fuels, from 18,333 mn tonnes in 1980 to $28,003 \mathrm{mn}$ tonnes in 2006 . 
Figure 20 shows that, with the exception of France, which has significant nuclear input to electricity generation, most countries show only a small drop in carbon intensity. The levels for China and Japan have recently been rising, the former on a base of coal-fired power. Over the 20-year period to 2000 the world ratio has declined by less than $0.4 \%$ per annum. Policies to reduce this ratio include nuclear and renewable power, coupled with electric drive technology. While reduction in emissions ratios will assist in reducing man's impact on climate change, the other strategy is to reduce both per capita energy consumption and energy intensity/GDP, the trends of which are shown in figure 11. Here reduction has been more successful, with world energy intensity declining by about $2.4 \%$ per annum. Offset against this has been a rise in population of nearly $1.6 \%$ per annum.

The fourth assessment report of the IPCC sets out a range of scenarios of $\mathrm{CO}_{2}$ emission reductions for increasing levels of global temperature and sea levels. Non of the scenarios includes for a rise in temperature of less than $2^{\circ} \mathrm{C}$, and it is to be assumed that IPCC regard some rise in temperature as inevitable. The strategy that achieves the lowest estimated increase in temperature and sea levels is the one that requires the greatest reduction in $\mathrm{CO}_{2}$ emissions. It is inevitable that some countries may be more committed than others, and some may feel that their input should be less than others by virtue of history and their relative economic development. Table 2 abstracts data from the IPCC table:

Table 2 IPCC Stabilisation Scenarios

\begin{tabular}{|c|c|c|c|}
\hline \multirow{2}{*}{$\begin{array}{c}\text { Stabilisation } \\
\text { Scenarios }\end{array}$} & $\begin{array}{c}\text { Change in Global CO2 } \\
\text { emissions in 2050 (percent } \\
\text { of 2000 emissions) }\end{array}$ & $\begin{array}{c}\text { Global Average Temperature } \\
\text { Increase above pre-industrial } \\
\text { at equilibrium }\end{array}$ & $\begin{array}{c}\text { Global average sea level } \\
\text { rise above pre-industrial } \\
\text { at equilibrium }\end{array}$ \\
\cline { 2 - 4 } & $\%$ & ${ }^{\circ}$ C & Metres \\
\hline I & -85 to -50 & $2.0-2.4$ & $0.4-1.4$ \\
II & -60 to -30 & $2.4-2.8$ & $0.5-1.7$ \\
III & -30 to +5 & $2.8-3.2$ & $0.6-1.9$ \\
IV & +10 to +60 & $3.2-4.0$ & $0.6-2.4$ \\
V & +25 to +85 & $4.0-4.9$ & $0.8-2.9$ \\
VI & +90 to +140 & $4.9-6.1$ & $1.0-3.7$ \\
\hline
\end{tabular}

Source: IPCC AR4 Table 5.1

IPCC set out a number of areas of $\mathrm{CO}_{2}$ mitigation, including energy (electric and non-electric) transportation, buildings, industry, agriculture, forest and waste management, along with cost estimates of strategies to meet potential savings (as a percent of GDP), which rise, the greater is the reduction in emissions to be achieved.

Temperature rises at scenarios III and upwards are likely unacceptable in terms of their results on the environment.

It is intuitive to work back from a particular scenario to see the implications of a reduction in emissions. For example, in Scenario I a reduction of $85 \%$ in emissions against 2000 levels would imply (from table 1) world emissions in 2050 of 23,850 $-85 \%=3,577.5 \mathrm{mn}$ tonnes $\mathrm{CO}_{2}$ (assuming that fossil emissions are in proportion to other emissions). Working back further, if no improvements in emissions intensity were achieved over 2000, this would imply, from the last column table 1 , a level of world GDP of only 3,577/0.4907 = \$7,290bn (compared to \$48,600bn in 2000). Working back still further, if it is assumed that population grows to $9 \mathrm{bn}$ by 2050 , then the level of world GDP per capita at 2050 would be $\$ 7,290 / 9=\$ 810$ per capita, only $10 \%$ of the world level of $\$ 7,993$ in 2000 .

Clearly the above hypothetical example is somewhat unlikely; in particular, that reductions in the intensities of emissions and energy to GDP are taking place, as noted earlier. These may continue to improve, if actions are taken by member states of the global economy to invest in relevant capital stock and technologies to mitigate climate change. Rises in population size may, however, dilute the level of GDP per capita.

Table 3 sets out a hypothetical example of progression from 1980 to 2050 , assuming that world $\mathrm{CO}_{2}$ output declined by $2.4 \%$ per annum from 2002 onwards to reach a level of 7,155 Gt pa, a reduction of $70 \%$, not far from the IPCC maximum reduction of $85 \%$ set out at table 2 . In passing it should be noted that table 1 shows that the carbon level rose $17.4 \%$ from 2000 to 2006. Thus already the world is behind on this projection. The other key assumptions made in table 3 are that carbon intensity reduces by $0.5 \%$ pa and energy intensity reduces by $2.0 \%$ pa, on a base of some continuation of efficiency improvements and some changes in habit. Last, it is assumed that world population continues to grow to reach a level of $9 \mathrm{bn}$ by 2050 , in line with the US Census Bureau projection. The calculations in the table are carried in reverse, that is, from carbon target to primary energy consumption, then to GDP and last to GDP per capita. 
Table 3 Projections to 2050 of Carbon Emissions*, Primary Energy Consumption, GDP, Population and GDP per Capita

\begin{tabular}{|c|c|c|c|c|c|c|c|c|c|}
\hline & $\begin{array}{r}\mathrm{CO}_{2} \text { Output } \\
\text { mn toe pa }\end{array}$ & $\begin{array}{r}\text { Carbon } \\
\text { Intensity } \\
\mathrm{CO}_{2} / P E C \\
\text { ratio }\end{array}$ & $\begin{array}{r}\text { Primary } \\
\text { Energy } \\
\text { Consumption } \\
m n \text { toe pa }\end{array}$ & $\begin{array}{r}\text { Energy } \\
\text { Intensity } \\
\text { Energy/GDP } \\
\mathrm{Kgoe} / \$\end{array}$ & $\begin{array}{c}\text { GDP PPP * } \\
\text { bn } \$ p a\end{array}$ & $\begin{array}{r}\text { Population } \\
m n \\
\end{array}$ & $\begin{array}{r}G D P / H d \\
\$ p a \\
\end{array}$ & $\begin{array}{r}P E C / H d \\
\text { toe } p a \\
\end{array}$ & $\begin{array}{r}\text { Emission } \\
\text { Intensity } \\
\text { CO2/GDP } \\
\mathrm{Kg} / \$\end{array}$ \\
\hline 1980 & 18333.3 & 2.7602 & 6641.9 & 0.3122 & $\$ 21,272.1$ & 4451.0 & $\$ 4,779$ & 1.492 & 0.8618 \\
\hline 1990 & 21426.1 & 2.6349 & 8131.6 & 0.2638 & $\$ 30,820.3$ & 5280.5 & $\$ 5,837$ & 1.540 & 0.6952 \\
\hline 2010 & 18700.0 & 2.4300 & 7695 & 0.1565 & $\$ 49,170$ & 6800.0 & $\$ 7,231$ & 1.132 & 0.3803 \\
\hline 2020 & 14660.0 & 2.3100 & 6346 & 0.1279 & $\$ 49,632$ & 7500.0 & $\$ 6,618$ & 0.846 & 0.2954 \\
\hline 2030 & 11490.0 & 2.1900 & 5247 & 0.1045 & $\$ 50,222$ & 8100.0 & $\$ 6,200$ & 0.648 & 0.2288 \\
\hline 2040 & 9010.0 & 2.0900 & 4311 & 0.0853 & $\$ 50,510$ & 8600.0 & $\$ 5,873$ & 0.501 & 0.1784 \\
\hline 2050 & 7155.0 & 1.9800 & 3614 & 0.0697 & $\$ 51,823$ & 9000.0 & $\$ 5,758$ & 0.402 & 0.1381 \\
\hline
\end{tabular}

* From consumption and flaring of fossil fuels

It can be seen that world GDP per capita projected on this basis is likely to stagnate to 2050 if the world adheres to the emission targets recommended by IPCC. The actuality in between 2000 and 2050 is likely to be a good deal different to the projection above, taking into account 'same as usual' trends, delayed action to implement policies, non-adherence and the paths of individual countries. Some countries, in particular, Russia, China, Australia, Canada and USA have very high emissions intensity ratios $\left(\mathrm{CO}_{2} / \mathrm{GDP}\right)$ to contend with. It is quite possible that reductions of emissions to the above low levels may not be achievable.

The overall emission intensity reduction from 2000 (the based level assumed by IPCC) to 2050 in the above example is from 0.4907 down to 0.1381 , equivalent to a reduction of $71.8 \%$. This figure is diluted in terms of GDP per capita, however, by an increase in world population of $48 \%$. If population had remained level, GDP per capita would have risen.

A means of illustrating the impact on GDP per capita of varying emissions intensity across the range of emission change requirements stated by IPCC to 2050 is set out at figure 21 .

Figure 21 World GDP per capita as a function of Global Carbon Emissions Change

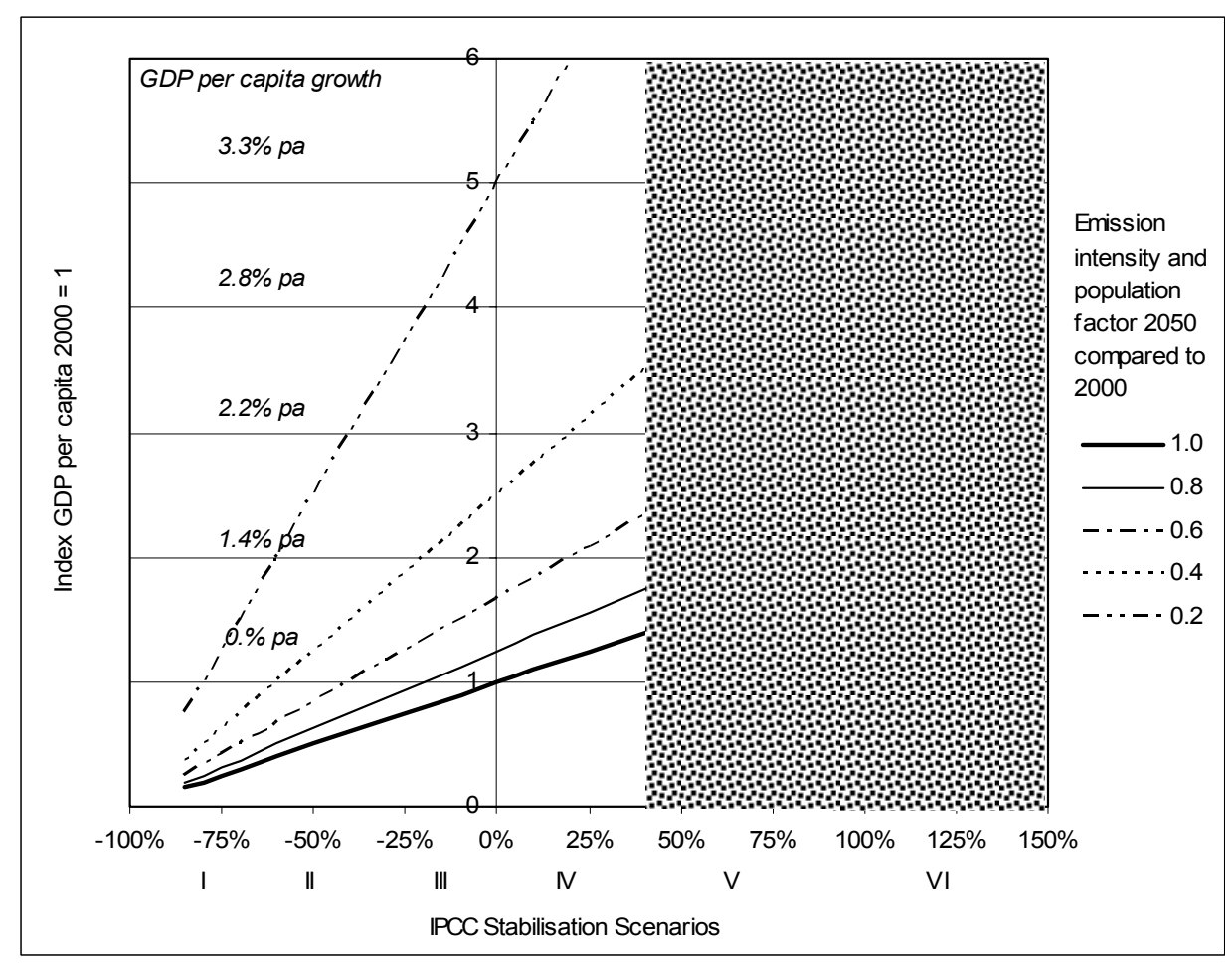


The range of IPCC stabilisation scenarios from table 2 is placed along the X-axis of the chart, with areas progressively shaded according to the increase in emissions and expected increases in global temperatures and sea levels. For low temperature rises only category I and perhaps II are viable, limiting policy consideration only to the left-hand part of the chart. An index of world GDP per capita is placed along the Y-axis, with the idex of GDP per capita at year 2000 (\$7,993 PPP constant prices) set at 1 . While the author would no longer support projections of exponential growth, some approximate equivalents are set out for each index level to help readers. Thus, for example, an index of 5 in 2050, compared to 1 in 2000 , would represent growth of $3.3 \%$ over 50 years between 2000 and 2050. As noted earlier, the position has deteriorated since 2000 with emissions at 2006 up by $17 \%$, and population increased by $7.5 \%$. Thus the world economy is currently marching towards the north-east part of the chart.

Splayed out across the chart is a range of world emission and population intensity factors, where 1 represents the position in year 2000. Table 3 shows this to be an emission intensity of 0.4907 combined with a population of $6.08 \mathrm{bn}$. At the upper end a factor of 0.2 , for example, might represent a combination of an increased population to $9 \mathrm{bn}$ combined with a reduction in emission intensity from 0.4907 in 2000 down to 0.0663 in 2050 , the latter about half the level of 0.1381 given in the example at table 3 .

It is a matter of evidence as to how far down the emissions intensity can be driven. Clearly if all countries emulated France in its nuclear programme, undertook extensive electricity programmes in non-renewable sources, and switched road transport into electrically driven mode, then some advances beyond the thermodynamic limits of fossil-fired energy might be possible. Over a 40-year period changes on consumer habits might also be engineered, particularly if faced with unpalatable energy costs and loss of living standards. A drop in population projection below $9 \mathrm{bn}$ would also help. The alternative is for the world to settle for a higher temperature rise, with the global risks that such a strategy would entail.

The above analysis adds weight to the conclusions concerning energy resources that the next half decade will likely follow a far different path than one based on projecting GDP on an escalating, exponential basis. No account has been taken in this paper of other factors, such as agriculture, fishing, water, and the move to an urban rather than a rural life. These latter factors will on the balance of probability likely add further weight to the analysis. There is likely to be a significant shift to the left in equation (3.1) of this paper. Thus no single reaction kinetic, as set out at section 4, is likely to describe the forward path. The particular path that world economic development will follow is likely to be quite complex, given the interactions of the many parties involved, and that currently the world is still proceeding in the opposite direction to the recommendations of IPCC.

A more promising approach may be to build a model based on a systems dynamic approach. Such an approach was attempted by Meadows for the Club of Rome in 1972, spawning a book 'The Limits to Growth', [Meadows et al (1972)] echoing perhaps concerns of Malthus [Malthus, T. R. (1798)]. The book subsequently lost interest as economic development proceeded apace. It has recently been reviewed however by Turner [Turner, G. (2008)] who concluded that 30 years of historical data compared favourably with the "business-as-usual" "standard run" scenario of Limits to Growth, but did not compare favourably with other scenarios involving comprehensive use of technology or stabilizing behaviour and policies.

To summarise however, climate change places a restriction on the forward path of output, inducing the equilibrium position to move backwards, in line with the thesis put forward by this paper.

This paper develops and illustrates a theory originally set out in a paper published by the author in 2007 [Bryant. J, (2007)]. The model is based on the well-known ideal gas equation, but set out in economic rather than thermodynamic terms, with pressure replace by price and temperature replaced by an index of trading value or velocity of circulation. Equivalent quantities of money flow in the opposite direction to products, resources and labour.

The first part of the paper concerns a general stock model, and defines parameters such as lifetime of units and nominal inherent productive content, with equations linking all the parameters. The inherent productive content of each and every unit of any factor is measured in terms of what it can do or pass on when it is consumed. The equivalent value in an energy context is called exergy, measuring the relative value distance of a unit from the environmental average. It was pointed out that economics defines the opposite flows of money in terms of labour and capital stock costs attached to each unit, such as wages and profits. The general stock model was developed for each of the types of stock met in an economic system, including money, labour, capital stock, resources, and environmental/waste stocks. 
A production function is developed, which is based on the Le Chatelier Principle, commonly used in physical and chemical systems. The function was similar in appearance to the Cobb Douglas function, familiar to economists. The key differences, however; are that first, the Le Chatelier system has a two-way relation between inputs and outputs, influencing the rate of reaction, An automatic forward reaction is not assumed as in the Cobb Douglas function. The second difference is that resources and waste are included, as well and capital stock and labour. Last, the relative forward and reverse forces are dependent upon the relative quantities available for each factor in the process. Thus the Le Chatelier system is continually in a state of flux and disequilibrium.

An equation for the production function is developed, which is similar in construction to the Arrehenius equation; an expression used in chemical kinetics to link the rate of reaction to the concentrations or availabilities of the reactants and products. It is similar in appearance to a Cobb Douglas function with a Hicks' neutral technical progress function added. Unlike the Hicks function however, the Le Chatelier system does assume that exponential growth can be projected into the future, without regard to the availabilities and impacts of resources and products.

A number of simple kinetic functions are developed, including a depreciation function, a two-way investment/depreciation function, a progressive reaction from one product to another and then to another, and last a resource function, based on Sshaped logistic saturation curves, with a peak output occurring at about the middle of the function. These functions are related to differential equations commonly used in systems dynamics.

Following on from the theoretical/mathematical exposition, analyses of the world energy market are set out to illustrate some of the principles.

First, analyses of primary energy, electricity consumption, GDP, population and capital stock are set out over time, to show how the world economy and specific countries have become progressively embedded in an energy base, with well-defined relationships between them all, such as energy and electrical intensity, energy/capital stock, and capital intensity with respect to population. These relationships show clear long-term trends over several decades, and show the extent (or not) that the world economy is adapting and improving its use of energy in GDP.

Second, analyses of energy reserves are set out to show the potential for reserve depletion of oil, natural gas and coal stocks, and the knock-on effect to GDP. There is evidence that world oil reserves are approaching a mid-point, beyond which production will decline steadily, as it did in the USA in the 1970s. The positions of natural gas and coal reserves are further behind in development. The conclusion is that extrapolating GDP exponentially into the future on the basis of continued availability of ever increasing fossil energy reserves is a false premise, and that feedbacks along the line of the Le Chatelier process will reduce the forward path, unless the world economy can adapt to manage with less fossil energy, and change its capital stock structure to other forms of energy such as nuclear and wind.

Third, studies carried out by the IPCC and other agencies all point to the necessity of reducing or containing the impact of greenhouse gases on the world environmental climate. More than half of all carbon emissions arise from consumption and flaring of fossil fuels. Although emissions intensity $\left(\mathrm{CO}_{2} / \mathrm{GDP}\right)$ has reduced, overall carbon emissions have continued to rise over several decades on the back of growth in world GDP. This trend is continuing, with a likely worsening of the climate change position.

Two analyses are set out to show the effect on GDP per capita, of attaining a reduction of $70 \%$ in $\mathrm{CO}_{2}$ emissions by 2050 , a little below the largest reduction of $85 \%$ proposed by IPCC. The first analysis shows the effect of a $72 \%$ reduction on emission intensity/GDP by 2050 combined with an increase in world population to $9 \mathrm{bn}$ (2000 6.08bn). The net effect is for stagnation in world GDP per capita from $\$ 7993$ in 2000 down to $\$ 5,758$ in 2050 , an overall reduction of $28 \%$. For reductions in emissions intensity below $72 \%$, the reduction in GDP per capita is worse if the world follows a low carbon emissions strategy. The second analysis shows the effect of varying the combination and emission intensity and population. The probability is that, even with a very large reduction in emission intensity or some reduction in world population, world GDP per capita is likely to follow quite a low trajectory to 2050 , likely at least less than $1 \%$ per annum, and much less than in the last two decades. Thus climate change places a restriction on the forward path of output, inducing the equilibrium position to move backwards, in line with the thesis put forward by this paper.

The particular path that world economic development will follow is likely to be quite complex, given the interactions of the many parties involved and that currently the world is still proceeding in the opposite direction to the recommendations of IPCC. No single reaction kinetic, as set out at section 4, is likely to describe the forward path wholly, and a more promising area may be to build models based on a systems dynamic approach. 
Ayres, R.U. Warr, B. (2003) ‘Two paradigms of production and growth'. CMER, INSEAD.

Bryant, J. (1982) ‘A thermodynamic approach to economics’, Energy Economics, Vol. 4, No. 1, pp.36-50.

Bryant, J. (2007) 'A thermodynamic theory of economics'. Int. J. Exergy, Vol 4, No. 3, pp. 307-337.

Bryant, J. (2008) 'A thermodynamic approach to monetary economics'. Working papers, Economic Consultancy, Vocat International.

Candeal, J.C. De Migule, J.R. Indurain, E. Mehta, G. B. (2001) 'Utility and entropy', Economic Theory, Springer-Verlag, 17, pp.233-238.

Cobb, C.W. Douglas, P.H. (1928) ‘A theory of production'. American Economic Review, 18 (Supplement), 139-165

Costanza R, Hannon B. 1989. Dealing with the mixed units problem in ecosystem network analysis. In: F Wulff, JG Field, KH Mann (eds) Network Analysis in Marine Ecology: Methods and Applications pp.90-115. Berlin: Springer.

Costanza R. 1980. Embodied energy and economic valuation. Science 210: 1219-24.

Georgescu-Roegen, N. (1971) ‘The entropy law and the economic process', Harvard University Press, Cambridge, MA.

Georgescu-Roegen, N. (1979) ‘Energy analysis and economic valuation', Southern Economic Journal, 45, pp.1023-1958.

Goldberg, R.N. Tewari, Y.B. Bhat, T.N. (1993-1999) 'Thermodynamics of enzyme-catalysed reactions Parts 1-5', Journal of Physical and Chemical Reference Data.

Hammond, G.P. (2004) 'Engineering sustainability: thermodynamics, energy systems and the environment', International Journal of Energy Research, 28, pp.613-639.

Hammond, G.P. \& Winnett, A.B. (2004) 'Some interdisciplinary perspectives on environmental appraisal and valuation', Towards an Environmental Research Agenda: A Third Selection of Papers', Palgrave MacMillan, Basingstoke, Ch.1, pp.333 .

Hannon, B. (1973) 'An energy standard of value'. Annals of the American Academy, 410: 139-153.

Hau, J.L. Bakshi, B.R. (2004) 'Promise and Problems of Emergy Analysis', Ecological Modelling, Ohio State University, Columbus, Ohio, 178: 215-225.

Hicks, J. (1932) 'The theory of wages'. Macmillan, London.

Hubbert, M K. (1956) 'Nuclear energy and the fossil fuels'. American Petroleum Institute, Spring Meeting, Southern District.

Kay, J. \& Schneider, E. (1992) 'Thermodynamics and measures of ecosystem integrity', Ecological Indicators', Elsevier, New York, pp.159-191.

Kamps, C. (2004) 'New estimates of government net capital stocks for 22 OECD Countries 1960-2001'. Kiel Institute for World Economics.

Laherrere, J (2005) 'Forecasting production from discovery'. ASPO. Lisbon May 19-20, 2005.

Laherrere, J (2006) 'Fossil fuels: What future?' China Institute of International Studies. Workshop October 2006, Beijing.

Lisman, J. H. C. (1949) 'Econometrics statistics and thermodynamics'. Netherlands Postal and Telecommunications Services. The Hague, Holland Ch IV.

Malthus, T. R. (1798) ‘An essay on the principle of population'. 
Meadows, D. H. Meadows, D. L. Randers, J. Behrens III, W. W. (1972) 'The limits to growth'. Universe Books.

Odum, H T. (1971) 'Environment, power \& society’, Wiley, London.

Odum, H T. (1998). 'Emergy evaluation', International Workshop on Advance in Energy Studies, Porto Venere Italy.

Patterson, M. (1998) 'Commensuration and theories of value in ecological economics', Ecological Economics, 25 pp.105125

Pikler, A. G. (1954) 'Optimum allocation in econometrics \& physics’, Weltwirtschaftliches Archiv.

Ruth, M. (1993) 'Integrating economics, ecology and thermodynamics'. Kluwer Academic, Dordecht

Samuelson, P. A. (1970) 'Maximum principles in analytical economics', Nobel Memorial Lecture. Massachusetts Institute of Technology, Cambridge, MA.

Samuelson, P. A. (1964) ‘An extension of the Le Chatelier principle’ Econometrica, 28, pp. 368-379.

Schneider, E. D. (1987) ‘Schrödinger shortchanged’. Nature 328, 300.

Schneider, E. D. Kay J.J. (1995) 'Order from disorder: The thermodynamics of complexity in biology', What if life: The next fifty years. Reflections on the future of biology’, Cambridge University Press, pp.161-172.

Schrödinger, E. (1944) 'What is life?' London: Cambridge University Press.

Söllner, F. (1997) 'A re-examination of the role of thermodynamics for environmental economics', Ecological Economics, $22,175-201$.

Sousa, T. Domingos, T. (2005) 'Is neoclassical microeconomics formally valid? An approach based on an analogy with equilibrium thermodynamics’, Ecological Economics, in press, corrected proof available online.

Turner, G. (2008) 'A comparison of the limits to growth with thirty years of reality'. Global Environmental Change, vol 18, issue 3, pp. 397-411.

Zittel, W. Schindler, J. (2007) ‘Coal: Resources and future production’. Energy Watch Group, EWG-Series No1/2007.

\section{$8 \quad$ Sources of Data}

BP Statistical Reviews 2001-2008.

Energy Information Administration, US Department of Energy.

IEA (2008[1]) 'Worldwide Trends in Energy Use \& Efficiency'.

IEA (2004) 'World Energy Outlook'.

IEA (2008) 'World Energy Outlook'.

Intergovernmental Panel on Climate Change; Third Assessment Report, Fourth Assessment Report (AR4).

OECD.

Penn World. 